\title{
UEBER DIE QUELLEN CYMBELINE'S.
}

Einen der beliebtesten stoffe, welchen dichter alter und neuerer zeit bearbeitet haben, bildet die rechtfertigung und verherrlichung eines schönen weibes, welches beschuldigt wird die gattentreue gebrochen zu haben. Vornehmlich ist das mittelalter an dichtungen reich, die diesen gegenstand zum inhalt haben. Die meisten derselben gehören der romanischen literatur an. Unter ihnen erregen diejenigen ein besonderes interesse, welche mit einer wette anf die treue der schönen beginnen und damit zugleich das thema von vornherein bekannt geben. Die geschichte erhält dann folgende fassung. Ein mann rthmt in gesellschaft anderer die zilchtigkeit und treue seines woibes. Dieses lob erweckt die eifersucht eines seiner zuhörer so sehr, dass dieser ihm eine wette darauf anbietet das weib furr sich zu gewinnen. Der gatte nimmt dieselbe an. Sein gegner begibt sich $z u$ der keuschen gattin und erklärt ihr seine liebe, wird aber abgewiesen. In der tiberzeugung seine wette verloren zu haben, wendet er sich an eine person, welche mit der getreuen in näherer beziehung steht. Mit hilfe dieser dritten person - gewöhnlich eines alten weibes - verschafft sich der tubeltiater zeichen, die augenscheinlich seinen erfolg beweisen. Auf grund derselben glaubt der gatte dem betrüger. Er verstösst sein unschuldiges weib und beabsichtigt es ermorden zu lassen. Dasselbe erträgt aber die ausbrüche seines zornes mit geduld, bis schliesslich der schändliche betrug entdeckt uud die gattin von dem verdachte der untreue vollständig gereinigt wird.

Die beweisführenden merkmale sind in den verschiedenen dichtungen verschiedener art. Gewöhnlich bestehen sie in einem male oder einer warze, welche sich auf der brust der schönen befindet; aber auch schon eine haarlocke, oder ein 
gürtel, ein armband oder eine börse kann den gatten von der treulosigkeit seines weibes iiberzeugen.

Auch die handelnden personen in diesen dichtungen gehören verschiedenen ständen an. Zumeist sind sie der bürgerlichen klasse entnommen, doch gibt es auch eine nicht geringe zahl solcher dichtungen, in welchen sie aus adels- und hof kreisen stammen.

Die heldin ist gewöhnlich eine verheiratete frau, zuweilen aber auch die braut, ja schwester des helden. - Auf dem gebiete der romanischen literatur begegnet man diesem thema zuerst in italienischen novellen und französischen romanzen, durch welche es sich in die deutsche und englische literatur verpflanzt hat. Die hier in betracht kommende italienische novelle ist die 9. des 2. tags des Decamerone von Boccaccio. Deutsche bearbeitungen dieser erzählung des Boccaccio sind z. b. die von Zacharias Liebhold von Solbergk ${ }^{1}$ und von Michael Kongehl. Eine noch ältere ist die comedia des Hans Sachs Von der unschuldigen frau Genura. Die älteste deutsche ist jedenfalls das gedicht: 'Von zwein Kaufmann', welches von einem Ruprecht von Würzburg verfasst ist und in die iibergangszeit vom 13. in das 14. jahrh. fällt. Dieses gedicht, welches sich abgedruckt findet in Grimm's 'Altdeutsche Wälder' bd. I, beruht allerdings auf einer französischen romanze.

Die wichtigste bearbeitung ist unstreitig die englische, das drama Cymbeline von Shakespeare. Wie es aber vol den erwähnten deutschen bearbeitungen feststeht, dass diese nur die italienische novelle zur quelle haben, der sie denn auch im ganzen ziemlich genau folgen; so ist es bis jetzt noch nicht entschieden, ob der dichter des englischen dramas, der

1 'Eine schöne' Historia von einem frommen gottesfïrchtigen Kaufmann von Padua, welcher zu Mantua im Beisein anderer Kaufleut wegen seines lieben frommen Weibes Ehr und Frömmigkeit, sein Hab und Gut verwendet, solches ihm aber ein leichtfertiger Sykophant mit Betrug und Unrecht abgewand.' S. Gottsched, 'Nöthiger Vorrath zur Geschichte der dramatischen Dichtkunst' Leipzig 1757 s. 139. Dieses stiick fällt in die zeit vor Shakespeare, dagegen nach Sh. das des Kongehl, in die achtziger jahre des 17. jahrhts. Es führt den titel: 'Der unschuldig beschuldigten Innocentien Unschuld. Eine nachdenkliche Genuesische Geschichte in einem Misch-Spiel'. Gottsched s. 243. Ueber das verhältniss dieses stiickes zu Cymbeline, s. Ang. Hagen: Shakespeare und Königsberg. ShakespeareJahrb. XV s. $325 \mathrm{f}$. 
seine vorlage in freier weise benutzt und erweitert hat, auch noch andere quellen hatte oder nicht; etwas bestimmt sicheres dartiber ist noch nicht gesprochen, da man die als entferntere quellen zu Cymbeline scheinenden dichtungen mit diesem drama noch nicht genau verglichen hat. Ich will nun versuchen das verhältniss derselben $z u$ diesem darzulegen und die frage zu erörtern: hat sich Shakespeare von diesen dichtungen beeinflussen lassen oder nicht? Dieser aufgabe gemäss halte ich es nicht fuir unniitz, einesteils an den inhalt des dramas kurz zu erinnern, teilweise den der als quellen in frage kommenden dichtungen genauer zu analysieren, und anderenteils auch das erst genau festzusetzen, was Shakespeare aus der italienischen novelle des Boccaccio und der chronik des Holinshed entnommen hat. Denn der umstand, dass diese beiden mit sicherheit als die bis jetzt feststehenden quellen des dramas anzusehen sind, bietet insofern einen anhalt, als man dann dichtungen, welche gar keinen neuen zug, sondern nur dinge bringen, welche Shakespeare aus jenen beiden vorlagen entlehnt hat, mit gewissheit zuriickweisen kann.

Die hier in frage kommenden dichtungen sind ausser der italienischen novelle, folgende:

1. Eine englische erziallung betitelt: 'The Tale told by the Fishwife of Standon-the-Green', welche sich in dem buche 'Westward for Smelts' findet.

2. Zwei altfranzüsische romanzen, welche beide vermutlich ein und derselben zeit, der ersten hälfte des 13. jahrhunderts, angehören. Die eine ist betitelt: 'Le Roman de la Violette on de Gérard de Nevers' und ist von einem Gilbert de Montreuil verfasst'; die andere fuhht den titel: 'Le Roman du comte de Poitiers.'

3. Ein altfranzüsisches mirakelspiel: 'Un Miracle de Nostre-Dame comment Ostes roy d'Espaigne, perdi sa terre par gagier contre Bérengier qui le tray et le fist faux entendre de sa femme en la bonté de laquelle Ostes se fioit; et depuis le destruit Ostes en champ de bataille.'

4. Das deutsche märchen von Sneewitchen, welches Karl Schenkl in Germania IV s. 458-50 mit dem drama Cymbeline in einigen punkten in enge beziehung gebracht hat.

1 Man vermutet, dass diese romanze eine französische novelle zur grundlage hat, die betitelt ist: 'Le Roman dou roi Flore et la belle Jehanne', und einige gelehrte sind der meinuing, dass die italienische novelle auf jener französischen romanze ruhe, während andere meinen, dass sie sich auf eine lateinische erzählung griinde. 


\section{Cymbeline.}

Akt I. Cymbeline, König von Britanien zur zeit des römischen kaisers Angustus, hatte von seiner ersten gemahlin eine tochter Imogen und zwei söhne Guiderius und Arviragus. Ein von ihm ungerechter weise verbannter hofmann Belarius hat aus rache diese beiden söhne in deren frïhester kindheit geraubt und lebt nun mit ihnen in der tiefsten waldeinsamkeit. Des königs zweite gemahlin, ein böses ränkevolles weib, hat ihm einen stiefsohn Cloten zugebracht, welchen sie mit Imog'en vermählen möchte. Diese hat sich aber schon mit Leonatus Posthumus, einem im gegensatz zu Cloten sehr tugendhaften edelmann, heimlich vermählt, welcher deshalb von Cymbeline verbannt wird. Posthumus geht nach Rom zul seinem freunde Philario, bei welchem er einige gefährten desselben trifft. Den stoff der unterhaltung bildet weibliche schönheit und tugendhaftigkeit. Einer von den freunden Philario's, Jachimo, spottet uiber die begeisterung; mit welcher Posthumus iiber die schönheit und treue seiner Imogen spricht, und verleitet ihn mit ihm in eine wette darauf einzugehen, dass auch Imogen seiner verführungskunst nicht widerstehen und dass er hiervon die deutlichsten beweise beibringen werde. Posthumus erklïrt sich $\mathrm{zu}$ dieser wette bereit. Jachimo reist darauf zu Imogen, wird aber von ihr abgewiesen.

Akt II. Durch eine verräterische list - er gelangt in einer kiste in das schlafgemach Imogen's - gewinnt er die nötigen beweismittel kenntniss von dem male auf ihrer brust und ein von ihrem gatten $\mathrm{z}$ geschenk erhaltenes armband - für seinen erfolg und gewinnt dadurch die sonderbare wette mit Posthumus, welcher nunmehr seine fiir treulos gehaltene gattin ermorden lassen will. - Der römische gesante Lucius fordert von Cymbeline im auftrage seines kaisers einen diesen schon lange schuldenden tribut.

Akt III. Lucius erklïrt dem Britenkönig den krieg, da er abermals den tribut verweigert, und schickt sich zur riickreise an. Pisanio, der bei Imogen zuriickgelassene treue diener des Posthumus, welchem letzterer den mord aufgetragen, entflieht mit ihr vom hofe ihres vaters, vereitelt aber den plan seines herren durch eine list: Imogen verkleidet sich als page und macht sich anf den weg nach Italien, um in die dienste des Lucius zu treten und in die nähe ihres gatten zu kommen. Auf ihrer wanderung gelangt sie ermattet zu einer höhle, welche dem Belarius und ihren briidern als aufenthaltsstätte dient. Hier wird sie von diesen, welche waidmannshandwerk betreiben, freundlich anfgenommen, ohne dass sie sich' gegenseitig erkennen. Cloten verfolgt in den kleidern des Posthumus die entflohene Imogen. - Lucius wird in Rom zum feldherrn des heeres ernannt, welches gegen Cymbeline geschickt wird.

Akt IV. Imogen fühlt sich krank, fällt aber in folge des trankes, durch den sie woler zu werden geglaubt, in eine todähnliche onmacht. Diesen trank, welchen die von ihrem arzte Cornelius getäuschte künigin fiir gift gehalten und den sie als stärkende arznei dem Pisanio gegeben, um ihn und Imogen aus dem wege zu räumen, hatte sie von dem diener zur erfrischung erhalten! Auch Cloten kommt an die höhle, wird aber vou Guiderius, den er zum zweikampf reizt, getötet; sein haupt wirft der- 
selbe in den voriberfliessenclen strom. Die vermeintlich tote Imogen und Gloten werden num beide zusammen in felsklifte bestattet. Hier erwacht Imogen und durch die falschen kleider getäuscht, hält sie Cloten's rumpf fïr den leichnam ilıres gatten. In tiefem schmerze uiber diesen verlust findet sie Lucins mit seinem heere, der sie in seine dienste nimmt. Belarins und seine pflegesïhne hören jetzt von der grossen gefahr, welche ihrem vaterlande durch das römische heer bereitet wird. Sie sind entschlossen gegen letzteres im vereine mit ihren landslenten zu kïmpfen.

Akt V. Posthumus von Pisanio mit der nachricht hintergangen, Imogen sei dem befehl gemaiss von ihm ermordet, hat sich dem römischen heere angeschlossen, $1 \mathrm{~m}$ in der schlacht scinen tod zu suchen. Er vertanscht aber bald aus vaterlandsliebe seine rümische riistung mit der eines britischen soldaten und kïmpft gegen die Römer, unter welchen sich auch Jachimo befindet. Als es jedoch scheint, dass die Briten siegen, geht er wieder zu dem römischen heere iiber und hofft nummehr $\sharp$ fallen. IIt hilfe des Belarius und seiner beiden pflegesöhne tragen die Briten den sieg davon. Posthumus, Iucius, Imogen, Jachimo und andere Römer werden getangen genommen. Der erstgenannte wird dem kerker iberliefert. Belarius, Guiderius und Arviragus, welche vorgeben, edelleute aus Cambria zu sein, werden zu ritter geschlagen und die römischen gefangenen \%um tode verurteilt. Da bittet Lucius fiir seinen trenen pagen Fidele so nennt sich Imogen in ihrer verkleidung - um nachsicht. Cymbeline, der an ihr gefallen findet, sichert ihr das leben zu. Auf veranlassung Imogen's gesteht Jachimo reuevoll ein, dass er sie verleumdet hat. Dieselbe gibt sich jetzt zu erkennen. Pisanio, wèlchen Imogen in verdacht hatte sie vergiften zu wollen, wird von diesem durch Cornelius befreit, welcher lie absichten der inzwischen verstorbenen künigin kund gibt. Cymbeline fiagt nach Cloten. Guiderius bekennt denselben getötet zu haben und wird deshalb zum tode verurteilt. In diesem augenblick entdeckt Belarius sich und dio beiden prinzen. Der künig, erfreut seine sülme widergefunden $z u$ haben, liisst Guiderius und Belarius unbestraft und gibt seiner tochter zu ihrer vermählung mit Leonatus Posthumus seinen väterlichen segen.

Das drama Cymbeline enthält zwei ganz von einander verschiedene erzählungen, deren eine auf den könig Cymbeline und seine beiden söhne sich bezieht; die andere die wette auf Imogen's treue zum gegenstande hat. Beide erzählungen hat Shakespeare in geschicktester weise vereinigt. Aus dieser verbindung entstanden die meisten unterschiede zwischen dem drama und seinen quellen.

Die erzählung von Cymbeline und seinen beiden söhnen findet sich bekanntlich in der chronik Holinshed's, welcher sich darin genau an den bericht des Galfied von Monmouth hält. Das, was hierron in beziehung zu Shakespeares drama steht, ist folgendes. 
Cymbeline wirde nach dem tode seines vaters Theomantius im jahre 3944 (728 nach der erbauung Roms und 33 vor Christi geburt) zum könig der Briten gewählt. Er soll in Rom erzogen, von Augustus Cissar zum ritter geschlagen worden sein und 35 jahre regiert haben. - Obgleich nun britische geschichtsschreiber berichten, dass sowol Cymbeline als sein vater Theomantius auf freundschaftlichem fusse mit den Rümern gelebt und ihnen den schuldigen tribut gezahlt hätten, so erzälilt Cornelius Tacitus, dass unter der regierung des Augustus, nach dem tode Julius Cäsar's, welcher ungefähr im 13. regierungsjalıre des Theomantius eingetreten, die Briten den tribut verweigert und sie deshalb zu bekriegen der römische kaiser dreimal im begriff gewesen, aber durch andere empörer stets zuriickgehalten worden sei. Galfred unterstiitzt die angabe der britischen historiker, dass sich Cymbeline stets als freund der Römer gezeigt habe. Als derselbe starb, hinterliess er zwei söhne namens Guiderius und Arviragus, von welchen jener als der altere der beiden briider den britischen tron bestieg. Aber Guiderius weigerte sich den Römern den tribut zu zahlen und so landete Claudius mit einem heere in Britannien. Der mann, auf welchen dieser kaiser sein grösstes vertrauen setzte, war Levis Hamo. Als der kampf begann, tat Guiderius wunder der tapferkeit und gerade in dem augenblick, wo Claudius auf sein schiff floh, warf der schlaue aber falsche Hamo seine waffen weg, zog die riistung eines britischen soldaten an und kämpfte gegen die fliehenden Römer. Er ermutigte die Briten diese zu verfolgen, um einen vollständigen sieg zu erringen. Allein in diesem kriegslärm näherte er sich Guiderius und tödete ihn. Daranf kehrte er zu dem rümischen heere zuriick, gegen welches nunmehr Arviragus die Briten fuihrte.

Aus diesem berichte nahm Shakespeare, abgesehen von den namen Cymbeline, Guiderius und Arviragus, hauptsächlich zwei tatsachen. Die eine besteht darin, dass die Briten sich weigern den Römern den schuldigen tribut zu zahlen, weshalb es zum kriege kommt. Aber entweder hat sich der dichter an die ansicht, welche Holinshed ans Tacitus überliefert, gehalten, dass Cymbeline es war, der den tribut nicht zahlte, oder er hat die gleiche angabe von Guiderius auf dessen vater ubertragen; denn in seinem drama verweiger $\overleftarrow{t}$ nicht jener, sondern dieser den tribut. Die andere tatsache, welche Shakespeare der chronik Holinshed's entlehnt hat, ist die, dass Leonatus Posthumus gleichwie Levis Hamo seine rüstung wechselt und zuerst als Brite gegen die Römer und dann als Römer gegen die Briten kämpft. Ausserdem entnahm der dichter derselben chronik alle in seinem drama vorkommenden stellen historischen inhalts.

Diese sind folgende. Die erste findet sich akt I, sc. $I$ und bezieht sich auf den vater des Posthumus. 
'- - His Father'

Was call'd sicillius, who did ioyne his Honor

Against the Romanes, with Cassibulan,

But har his 'Titles by Tenantius, whom

He seru'd with Glory, and admir'd Successe:

So gain'd the Sur-addition, Leonatus'.

In alit III, sc. 1 weist der künig Cymbeline den rümischen gesanten Lucius auf den sieg des Cassibulan und dessen feier in London hin.

'Remember Sir, my Liege,

The King's your Ancestors, together with

The naturall brauery of your Isle, which stands

As Neptunes Parke, ribb'd, and pal'd in

With Oakes vnskaleable, and roaring Waters,

With Sands that will not beare your Enemies Boates, But sucke them vp to'th' 'Top-mast. A kinde of Conquest

Caesar made heere, but made not heere his bragge

Of Came, and Saw and Ouer-Came: with shame

('The first that ener touched him) he was carried

From off our Coast, twice beaten: and his Shipping

(Poore ig'norant Baubles) on our terrible Seas

Like Egge-shels mou'd vpon their Surges, crack'd

As easily gainst our Rockes. For ioy whereof,

The fam'd Cassibulan, who was once at point

(Oh giglet Fortune) to master Caesars Sword,

Made Luds-'Towne with reioycing-Fires bright,

And Britaines strut with Courage'.

Eine dritte stelle bildet einen weiteren teil derselben scene und handelt von Mulmutius, dem ersten könige der Briten. Nachdem Cymbeline dem Lucius gesagt, dass die Römer ungerechterweise den tribut erpresst hätten, fährt er fort:

- Say then to Caesar,

Our Ancestor was that Mulmutius, which

Ordain'd our Lawes, whose vse the Sword of Caesar

Hath too much mangled; whose repayre, and franchise,

Shall (by the power we hold) be our good deed,

Tho Rome be therfore angry. Mulmutius made our lawes

Who was the first of Britaine, which did put

His browes within a golden Crowne, and call'd

Himselfe a king'.

Und als Lucius dem könig Cymbeline den krieg erklïrt hat, antwortet derselbe:

'Thou art welcome Caius,

Thy Caesar Knighted me; my youth I spent

Much vnder him; of him, I gather'd Honour

${ }^{1}$ Ich gebe hier und in folgenden stellen den text der folioausgabe von 1623 . 
Which he to seeke of me aigaine, perforce

Behooues me keepe at vtterance. I am perfect,

That the Pannonians and Dalmatians, for

Their Liberties are now in Armes: a President

Which not to reade, would shew the Britaines cold:

So Caesar shall not finde them'.

Von diesen Pannoniern und Dalmatiern berichtet Holinshed, dass sie sich beide gegen Augustus Cüsar empörten, als dieser gegen Britannien krieg führte, so dass er sich genötigt sah die kämpfe mit den Briten abzubrechen, um eben zuerst jene aufstände zu unterdrücken, welche Rom näher und deshalb gefährlicher waren.

Hat nun Shakespeare diese stellen nur inhaltlich dem chronisten entlehnt und sie in seiner eigenen sprache und form widergegeben, so hat er aber auch andrerseits vornehmlich in einer stelle manchen ausdrücken desselben sich angepasst. Dieselbe findet sich in der 3. scene des V. aktes, wo Posthumus mit einem hofman von der tapferkeit des Belarius und seiner beiden pflegesöhne spricht. Holinshed erzichlt in seiner chronik, als er von den kriegen zwischen den Schotten und Dänen handelt, von einem lord Hay und dessen beiden söhnen, dass sie

- 'when the Scots which fled were beaten down through a lane fensed on the side with ditches and walles made of turf' etc. 'and when the king was destitue of the 'wings' - 'Haie with his sonnes supposing they might best staie the flight, placed themselves overthwart the lane',

die Schotten von der flucht zuriuckhielten und

'cried unto their fellowes to returne backe unto the battell'.

Ganz dasselbe findet sich bei Shakespeare (V, 3). Posthumus erzählt dem britischen lord:

\section{- 'the King himselfe}

of his wings destitute, the Army broken,

And but the backes of Britaines seene; all flying

Through a strail Lane', etc.

Auf die frage des lord, wo diese gasse gewesen, antwortet Posthumus:

'Close by the battell, ditch'd and wall'd with turph,

Which gave aduantage to an ancient Soldiour

(An honest one I warrant) who deseru'd

So long a breeding, as his white beard came to, In doing this for's Country. Athwait the Lane He, with two striplings (Lads more like to run The Country base, then to commit such slaughter, With faces fit for Maskes, or rather fayrer Then those for preseruation cas'd, or shame), 
Marle good the passage, cryed to those that fled.

Our Britaines hearts dye flying, not our men,

To darknesse fleete soules that flye backwards; stand,

Or we are Romanes, and will giue you that

Like beasts, which you shun beastly, and may sane

But to looke backe in frowne: stand, stand' etc.

Endlich hat der dichter auch den namen 'Imogen' der chronik entnommen. Holinshed erwähnt denselben aber nicht in dem berichte iiber Cymbeline, sondern im eingang seines werkes, wo er von Brutus und Locrin spricht.

Dagegen berichtet der chronist nichts von einer heimlichen entfiihrung der beiden prinzen durch Belarius, und daher auch nichts von ihrem leben in der höhle und ihrer rïckkehr an des vaters hof. Da eine quelle hierfuir nicht aufzufinden ist, so wird die annahme notwendig, dass dieser zug von Shakespeare ersonnen worden ist. Auch uiber die königin und ihren sohn Cloten schweigt die chronik. Beide charakteren sind ebenfalls ein produkt seines schöpferischen geistes, wie auch Imogen als tochter des königs, welche der chronist als solche nicht kennt.

Für die hauptfabel des dramas Cymbeline bildet die 9. novelle des 2. tags des Decamerone von Boccaccio die quelle. Ob Shakespeare dieselbe aus dem original oder aus einer englischen bearbeitung kennen gelernt hat, lässt sich mit sicherheit nicht entscheilen. Mich bewegt zur annahme des letzteren der umstand, dass Shakespeare sonst in seinen anderen stticken, für die er italienische vorlagen hatte, diese in englischer iibersetzung oder bearbeitung benutzt hat, wiewol ich ihm eine kenntniss der italienischen sprache nicht völlig abspreche. Hatte er doch etwas Latein gelernt ${ }^{1}$ und wahrscheinlich auch mit dem grossen italienischen sprachmeister John Florio in verkehr gestanden. Auch finden sich in seinen stiicken eine menge italienischer ausdrücke. ${ }^{2}$ Da aber die früheste englische iibersetzung des ganzen Decamerone erst im jahre 1620 von Isaac Jaggard gedruckt worden ist, so muss angenommen werden, dass diese novelle zu denjenigen

'Auch in unserem stiicke bedient er sich einiger lateinischen ausdriicke, so I, 4 by 'ilems'; dann gibt er etymologien, so von Leonatus = leo-natus $(\mathrm{V}, 5)$ mulier $=$ mollis aer $(\mathrm{V}, 5)$.

${ }^{2}$ S. Alex. Schmid, Shakespeare-Lexicon 1874. Vol. II, s. 1427. 
gehört, die schon frïher iibersetzt worden waren und in dieser übersetzung verloren gegangen sind, ausgenommen die in Painter's Palace of Pleasure (1566 und 67) enthaltnen. Dass es englische iibersetzungen einzelner novellen des Boccaccio vor 1620 gab, beweist die dedication der übersetzung aus diesem jahre. Hier wird gesagt, dass schon lange vorher viele von den erzählungen veröffentlicht worden wären.

In der einleitung meiner abhandlung sagte ich, dass diese italienische novelle mit sicherheit als stoffquelle fuir Cymbeline anzusehen sei; Delius dagegen bedient sich des ausdrucks 'vielleicht'. Die sicherheit der entlehnung aus italienischer quelle beweisen die namen Philario, Pisanio und Jachimo, einige italienische ausdriicke im stiicke selbst und vor allen einzelne züge, die darin einen engen anschluss an die novelle erkennen lassen. Von Jachimo und Philario geht mit sicherheit hervor, dass sie Italiener sind; jener wird mit signior, der Franzose mit monsieur angeredet. Tarquinius nennt er seinen landsmann. In akt V, sc. 5 sagt er: mine Italian braine, Gan in your: duller Britaine operare Most vildely. Von italienischen formen kann man vielleicht auch 'a mole cinquespotted' anfihren; in der novelle ist diese form vorhanden in 'cinque millia fiorini'. Der name Philario ist weiter nichts als Filorio oder Florio, wie auch in der folio-ausgabe steht. Sollte dieser freund des Posthumus nicht nach dem sprachmeister 'Florio' g'enannt worden sein? Ich erspare mir hier eine analyse der novelle und verweise auf Delius ${ }^{1}$, Collier ${ }^{2}$, Simrock ${ }^{3}$ und Witte. ${ }^{4}$ Was Shakespeare dieser erzählung ẹntlehnt und daran yeandert hat, ist folgendes. Zunichst das tragische element seines stiickes, die fabel iuberhaupt, dass ein mann in eine wette auf die treue und standhaftigkeit seines weibes mit einem andern eingeht, der ihn durch einige merkmale täuscht, welche scheinbar die treulosigkeit seiner gattin beweisen, aber dessen schurkerei entdeckt wird, so dass das ehrbare weib am ende den sieg der tugend erringt. Bernabo Lomellin ist Leonatus Posthumus, Ambrogiuolo ist das abbild Jachimo's und

${ }^{1}$ Einleitung zu Cymbeline, Shakespeare's Werke. 4. auflage. Elberfeld 1876. Bd. II s. 609 .

2 Shakespeare's Library. London 1875. Vol. II.

3 Ueber die Quellen Shakespeare's. 2. aufl. 1872. Bd.-2.

4. Witte's Uebersetzung des Decamerone. Leipzig 3. aufl. Bd. I. 
in Ginevra erblickt der leser Imogen. Der verbindung dieser novelle mit der geschichte von Cymbeline ist es zuzuschreiben, dass die handelnden personen, nicht wie bei Boccaccio den buirgerlichen, sondern zum grössten teil den hofkreisen angehören. Von einzelnen ziigen ist zunächst beiden gemein, dass jeder der gatten sein schönes weib als geschenk gottes betrachtet. Bernabo Lomellin versichert 'di spezial grazia da Dio avere una donna per moglie' etc. Posthumus sagt I, 5:

"The other (Imogen) is not a thing for sale, and only the guift of the Gods, which by their Graces I will keepe'.

Uebereinstimmend mit der novelle ist ferner der versuch Philario's die wette zu verhindern, sowie der zug, dass der inhalt der wette genau zu papier gebracht wird. Im stiicke sagt Posthumus I, 5 :

'Let vs haiue Articles betwixt vs.'

Jachimo sagt ebenda:

'Your hand: a Covenant. Wee will haue these things (die bedingungen der wette) set downe by lawful Counsell'.

In der novella wird erzählt: 'Per belle scritte di lor mano s' obligarono l' uno all' altro'. Dagegen sind die bedingungen, unter welchen die wette bei Boccaccio abgeschlossen wird, etwas anderer art, als die bei Shakespeare. Ambrogiuolo wettet um 5000 goldgulden und sichert sich einen zeitraum von drei monaten $z u$, innerhalb welchem es ihm gelingen werde Ginevra zu verfithren, sobald Bernabo abwesend sei. Jachimo dagegen setzt 10000 gulden auf den diamantring des Posthumus und bestimmt keine zeit, in welcher er zum ziel gekommen sein wirde, sondern behält sich vor, dass er gelegenheit habe mit Imogen zweimal zu sprechen und dass ihm Posthumus einen brief an seine gattin einhändigen werde, um durch diesen zugang bei ihr zu finden. Diese abweichung von der vorlage, welche noch verschiedene andere abänderungen derselben zur folge hat, erheischt deren dramatisierung. $\mathrm{Zu}-$ nächst wird es durch diesen brief nicht notwendig, dass Jachimo, wie Ambrogiuolo zu tun genötigt ist, ein altes weib besticht, um in Imogen's zimmer zu gelangen; sodann aber wird es ihm dadurch möglich mit ihr selbst zu sprechen, während dies in der novelle nicht der fall ist. Die art und weise, auf welche Jachimo zu den beweisführenden merkmalen gelangt, ist dieselbe, welche Ambrogiuolo anwendet. Beide schlüpfen in eine kiste, welche im schlafgemach der gattin aufgestellt wird; und 
diese tibereinstimmung ist es, welche sicher beweist, dass Shakespeare die fabel der novelle des Boceaccio entnommen hat. Denn weder in einer der altfranzösischen dichtungen noch in der englischen erzählung wird jener kiste erirähnung getan. Der umstand, dass Imogen im bette liest, ist vom dichter ersonnen; er wird zu einem weiteren beweismittel für Jachimo. Denn dass sie gerade aus der erzählung von Tereus die stelle gelesen, wo Philomele sich ihm ergibt, muss Posthumus in seinem glauben an Jachimo's erfolg nur noch bestärken. Der dentlichste beweis fur diesen ist dem Posthumus die kenntniss von dem male. Dieses findet sich nicht nur in der italienischen novelle, sondern auch in dem Roman de la Violette und dem Mirakelspiel, obgleich es hier nicht als solches, sondern nur als 'secrée enseigne' bezeichnet wird. Uelereinstimmend in diesen dichtungen ist ferner, dass sich dieses mal unter der linken brust ('sotto la sinisira.poppa') des weibes befindet. In der italienischen novelle erscheint es in begleitung von einem biischel (6) goldgelber haare. Von Shakespeare wird es dargestellt (II, 2) als 'On her left brest A mole Cinque-spotted, Like the Crimson drops I' th' bottome of a conslippe'. Als weitere belege für seinen erfolg dienen Ambrogiuolo ein ring, der gürtel, ein staatskleid und die börse Ginevra's; dem Jachimo das armband Imogen's. Der ring, welchen diese ihrem Posthumus schenkt und welchen Jachimo durch die wette gewinnt, spielt bei Shakespeare eine weit wichtigere rolle als in der novelle, wo er als einfaches beweismittel furr Ambrogiuolo's erfolg dient. Im drama ist sein zweck ein anderer, da fihhrt er das geständniss Jachimo's herbei, Imogen verleumdet und Posthumus betrogen zu haben. Dies bezwecken bei Boccaccio der gitirtel und die börse. Der ring als beweis für den erfolg des utbeltaiters findet sich auch in dem Roman du comte de Poitiers. Entscheidend dagegen fur die entlehnung des stoffes aus Boccaccio's novelle ist ferner der nur mit dieser allein gemeinsame zug des dramas, dass sich Jachimo - ganz wie Ambrogivolo - genau die gegenstände des schlafgemachs Imogen's notiert. Er sagt (Akt II, sc. 2):

'To note the Chamber, I will write all downe: Such, and such pictures - : There the window; such Th' adornement of her Bed; the Arras, Figures, Why, such, and such: and the Contents o' th' Story'. 
In der novelle wird erzählt: 'Per la qual cosa egli il sito' della camera, le dipinture et ogni altra cosa notabile che in quella era, cominciò a ragguardare, et a fermare nella sua memoria.' Natiirlich wird auch das zimmer der Ginevra wie das Imogen's durch ein licht erhellt. Uebereinstimmend ist ferner, dass beide gatten mit der beschreibung des zimmers und den gegenständen als beweise für den erfolg des uibeltäters nicht zufrieden sind, sondern demselben vorhalten, dass er durch irgend jemand zu alle dem gekommen sein könnte. Beide, sowol Ambrogiuolo als auch Jachimo, haben betenert die gegenstände von der gattin als geschenk erhalten zu haben. Von Ambrogiuolo heisst es: 'Affermando da lei averle avute'; Jachimo sagt: 'She gaue it me, And said, she priz'd it once'.

Ebenso senden beide gatten Bernabo und Posthumus ihre diener mit briefen an ihre frauen und beauftragen sie dieselben zu töten. Dagegen ist es widerum eine abweichung von Bocaccio, dass bei Shakespeare nicht das unglitckliche weil), sondern der diener den vorschlag macht manneskleider anzulegen. Ginevra verkleidet sich als matrose und geht in die dienste eines Cataloniers; Imogen wird page und begleitet als solcher den Römer Lucins. Dadurch hat der dichter die errithlung von Cymbeline mit der von Bernabo Lomellin glücklich vereint, und bis dahin hat ihm auch die italienische novelle ohne zweifel vorgelegen. Der weitere verlauf derselben ist aber ein anderer als der des dramas, und nur der schluss beider dichtungen ist derselbe, dass die übeltiiter entdeckt, die frauen aber von der schmach befreit werden. Wie so manche aibweichung Shakespeare's von seiner vorlage der dramatisierung: derselben zuzuschreiben ist, so ergibt sich darans auch die verschiedenheit in der zeichnung der charaktere. ${ }^{\text {Vor allem }}$

1. Die meinung Dunlop's: 'The scenes and the characters have been most unjudiciously altered' und 'those slight alterations which have been made do not seem to be improvements' und endlich 'the remaining part of the drama - wo sich Shakespeare von der novelle vollständig losgerissen hat - does as little honor to his invention as the preceding to his judgement' ist jetzt wie die ansicht Johnson's vollstïndig zurückgewiesen. 'T'o remark', sagt Johnson, 'the folly of the fiction, the absurdity of the conduct, the confusion of the manners of different times, and the impossibility of the events in any system of life, were to waste criticism upon unresisting imbecility, upon faults too evident for detaction, and too gross 
- ist der charakter des dieners in der novelle ein anderer als der Pisanio's im drama. Bernabo's diener ist zwar ebenso treu seinem herren als der des Posthumus, aber er fühlt nicht dasselbe mitleid für Ginevra als Pisanio für Imogen. Der grund dafür liegt darin, dass er nicht das motiv seines grausamen auftrags kennt, während Pisanio davon unterrichtet und von der unschuld seiner herrin fest überzeugt ist. Auch die eharactere der übrigen personen des dramas treten dem leser natürlich viel schärfer entgegen als die der entsprechenden in der novelle. Imogen ist die vertreterin jener sanften, reinen und tugendhaften weiblichkeit, welche das herz eines edeldenkenden mannes für immer fesselt. Thre keuschheit und standhaftigkeit sind starke waffen gegen alle gemeinen und frechen angriffe; selbst die versuche eines Jachimo scheitern an ihrer festigkeit. Aus liebe und treue zu Posthumus erträgt sie die bittersten schicksalsschläge und verlangt von Pisanio selbst ihren tod, da ihn ihr gatte wünscht. Posthumus zeigt die grösste sittenreinheit; er ist kein sensualist, sondern liebt Imogen ihres edlen charakters wegen. Nur, weil er sich der keuschheit und treue seines weibes zu sicher fühlt, nimmt er die wette an. Hätte er dieselbe zuriickgewiesen, so wäre dies vielleicht in den augen seines gegners ein beweis für vertrauensschwäche gegen Imogen gewesen. Keineswegs aber ist Posthumus von mängeln rein: energie des charakters geht ihm $\mathrm{ab}$, leichtgläubigkeit ist ihm eigen. Beides sind charakterschwächen, an welchen er vielleicht zu grunde gegangen sein würde, wenn das drama vom dichter als tragödie geplant worden wärè.

Im vorausgehenden habe ich ausführlicher, als bis jetzt getan worden ist, das verhältniss des dramas zu der italienischen novelle dargelegt, um eben die sîcherheit zu begründen, mit welcher dieselbe als vorlage zu Cymbeline anzusehen ist. Ich schliesse hieran betrachtungen über jene englische erzählung des fischweibes, tuber deren entstehungszeit und beziehung zu dem drama noch ein dunkel herrscht. Ich werde in folgendem aus inneren grtinden; abgesehen von der zeit ihres erscheinens, nach-

for aggravation:' - Gervinus (Shakespeare III s. 406 ff.) war einer der ersten, welche das drama Cymbeline als des dichters vollständig würdig erkannten und achteten. 
weisen, dass sie von Shakespeare nicht benutzt worden ist. Nur soviel möchte ich ïber die zeitfrage bemerken, dass das buch: 'Westward for Smelts', wenn es wirklich vor 1619 geschrieben, meiner ansicht nach auch vor dieser zeit noch gedruckt worden sein wïrde. Denn es enthält keine dramen, welche auch durch die biilıne bekannt werden konnten, sondern erzählungen, die im drucke erscheinen mussten, sollten sie dem volke dargeboten werden. Da Malone für seine behauptung auch nicht einen einzigen grund angibt, dass es schon eine vom jahre 1603 datierte ausgabe dieses buches gegeben habe, und dasselbe erst in den jahren 1619-20 in das register der buchhändlergilde eingetragen worden ist, so kann man wenigstens mit wahrscheinlichkeit auch seine abfassung in die zeit kurz vor 1619 setzen. Ich führe hier noch eine angabe John Arber's an, aus der man auch den verfasser: des buches erfährt.

Auf s. 309 des III. bandes seines 'Transcript of the Registers of the Company of Stationers of London' steht die notiz:

$15^{\circ}$ Januarii 1619 [i. e. 1620]

John Trundle Entred for his copie vnder the handes of Master Tauernor and Master Swinhowe warden, A booke Called Westward for Smeltes, written by Kinde Kitt of Kingston.

Wenn man über das leben dieses Kinde Kitt of Kingston aufschluss erhalten könnte, so wiirde man dann vielleicht das entstehungsjahr von Westward for Sneltes endgiltig feststellen können, und die unmöglichkeit einer benutzung dieser erzählung seitens Shakespeare würde gewiss wahrscheinlicher werden. Aber auch aus innern grïnden kommt man zu einem gleichen ergebniss. Selbst wenn das buch schon 1603 gedruckt worden wäre, so hat es auf Shakespeare keinen einfluss gehabt. Der inhalt dieser 'Tale told by the Fischwife of Standon-the-Greene' ist folgender:

Zur zeit Heinrich's des VI. lebte in dem nicht weit von London entfernten Waltam ein mann, der ein sehr schönes und tugendhaftes mïdchen geheiratet hatte. Eines tages war er in London und sah sich dringender geschäfte wegen genötigt daselbst in einem gasthaus über nacht zu bleiben, in welchem er beim abendbrot mit anderen kaufleuten zusammentraf. In ihrer unterhaltung kamen sie auch auf die frauen zu sprechen, deren tugendhaftigkeit einer der kaufleute sehr geringschützte. Als der junge gatte, welcher dadurch gereizt worden war, dagegen den 
schärfsten einspruch erhob, bot ihm dieser kaufmann eine wette an, dass es ihm innerhalb eines monats gelingen wiirde sein weib in Waltam zu verfibren und beweise ïber seinen erfolg zu bringen. Der gatte nahm die wette an und blieb in London zuriick, während sein gegner nach Waltam reiste. Daselbst spiegelte derselbe der jungen frau vor ein freund ihres gatten zu sein; er hätte den auftrag ibr zu melden, dass dieser notwendiger geschäfte wegen noch einige zeit in der hauptstadt bleiben muisste. Sie nahm ihn als freund ihres mannes gut auf und nur als sie seine absicht merkte, suchte sie ihn zu meiden. Der junge kaufmann iiberlegte mittel und wege seine wette zu gewinnen, und gebrauchte schliesslich folgende list. Er stellte sich krank und gieng am dritten tage seines dortseins früher zu bett als vorher, schlich sich aber in das schlafgemach der gattin, welches neben dem seinigen gelegen war, und kroch unter deren bett. Des nachts kam er aus seinem versteck hervor und entwendete ein kleines crucifix, welches die fran auf ihrer brust zu tragen pflegte. Dieses brachte er dem gatten als beweis seines erfolges. Derselbe schenkte seinem gegner glauben und beauftragte seinen diener George, welcher von der wette kenntniss hatte, sein weib von Waltam nach London zu bringen und es unterwegs zu töten; wïrde er dieses gebot nicht erfüllen, so sollte er selbst den tod erleiden. George gieng nach Waltam und nahm die unglïckliche frau mit sich nach London. Unterwegs warf er ihr ihre untreue gegen ihren gatten vor und schickte sich an sie zı ermorden. Da dieses loos des gemalles wille war, so forderte sie selbst George auf diesem gerecht zu werden, obgleich sie versicherte von aller schuld rein zu sein. Durch ihre worte geriihrt, schenkte er ihr das leben und schlug ihr vor sich als mann zu verkleiden. Darauf kehrte der diener nach Waltam zuriick und verwaltete die besitzungen seines herren, der inzwischen in die dienste des künigs Heinrich des VI. getreten war. Das ungliickliche weib lebte in manneskleidern zuniichst von dem gelde, welches es aus verschiedenen wertsachen gelöst hatte. Als es aber davon nichts mehr hatte, kam es in grosse not und gieng in die gegend von York, wo es sich von kräntern nährte. Hier begegnete das weib Eduard, dem kïnig von Frankreieh, welcher gegen Heinrich krieg führte. Eduard nahm es als pagen in seine dienste und begiinstigte denselben seiner guten fïhrung wegen auf's höchste. Es kam zur schlacht von Barnet, in welcher Eduard siegte. Das weib, das sich als, page 'Edmund' nannte, suchte ihren gatten in den reihen der gefallenen auf seiten Heintich's. Aber statt dessen fand sie den, welcher sie zu verfiihren versucht hatte. Als sie dessen wunde auf der brust ans mitleid verband, kan sie wider in den besitz ihres crucifixes. In dem dieb sah sie nunmehr den stifter ihres unglïcks. Sie fiihrte ihn zu Eduard, welchen sie von allem unterrichtete. Der könig liess den gatten rufen, welcher von den Franzosen gefangen genommen worden war. Der iibeltäter behauptete anfangs das crucifix gekauft zu haben, gestand es aber am ende doch ein, dass er es gestohlen habe, um den gatten zu täuschen. Der page entdeckte sich jetzt als die verläumdete frau. Der betrüger wurde mit einem jalr gefaingniss und dreifacher herausgabe des geldes bestraft, welches er durch die wette gewonnen hatte. Eduard war geneigt auch den 
gatten zu strafen, weil er auf eine solche wette eingegangen, bestimmte aber seine gattin selbst zum richter. Diese verzieh ihm und kehrte mit ihm nach Waltam zuriick, wo beide von George freudig empfangen wurden.

Vergleicht man diese novelle inhaltlich mit dem englischen drama, so lässt sich eine mehr oder minder grössere ïbereinstimmung nicht liaugnen. Aber es fragt sich, worin dieselbe besteht. Sind es punkte, die und deren anlässe sich auch in Holinshed's chronik und der italienischen novelle vorfinden, oder sind es solche, die nur den beiden englischen dichtungen zukommen? Dabei ist ferner alles das abzusondern, was mit notwendigkeit aus der verbindung der errählung von Cymbeline und seinen beiden söhnen und der novelle des Boccaccio und deren dramatisierung folgt. Fiir eine benutzung der erzählung des fischweibes seitens Shakespeare's künnte - selbstverständlich wenn man die angabe Malone's bona fide gelten lassen wollte - nur eine ïbereinstimmung solcher punkte sprechen, die das drama einzig und allein mit ihr gemein hätte. Doch ehe ich darauf eingehe, will ich einen blick auf die erzählung als dichtung werfen. Als solche trägt sie zweifellos ein ziemlich rohes und nuichternes gepräge. Eine poetische färbung geht ihr vollständig al. Die italienische novelle nimmt in dieser beziehung eine bedeutẹnd höhere stellung ein. Das fischweib berichtet in der ihm zukommenden denk- und sprechweise nur die einzelnen tatsachen, welche bei Boccaccio und in erster linie bei Shakespeare, aber auch in den meisten französischen dichtungen, in poetischem gewande erscheinen. Ausserdem unterscheidet sie sich aber auch sachlich in zwei sehr wesentlichen punkten von dem drama und seiner vorlage. Sie kennt weder die kiste, in welcher Jachimo und Ambroginolo in das schlafgemach der jungen gattin gelangen, noch das mal und den ring. Statt dieser für den beweis seines erfolges sicher stärker ins gewicht fallenden merkmale bringt der tibeltäter in dieser erzählung ein kleines crucifix. Wollte man einmal davon absehen, dass der ganze inhalt erdichtung: ist, so würde sicher dieser umstand entweder die ganze erzählung sehr unwahrscheinlich machen oder den gatten in das schlechteste licht stellen. Dagegen beweisen jene beiden punkte nur zu deutlich, dass Shakespeare die ganze fabel niçht aus dieser erzählung, sondern aus der italienischen novelle kennen ge- 
lernt hat. Die stellen, welche sie nur mit dem drama gemein hat, sind folgende:

1. Sowol in der erzählung als auch im drama wendet sich der verführer direkt an die gattin selbst; in der ersteren gibt er vor von ihrem gatten beauftragt zu sein, sie ïber den grund seines zuriickbleibens in London in kenntniss zu setzen, wïhrend in dem letzteren Jachimo in folge eines briefes von Posthumus an Imogen gelegenheit gewinnt mit derselben zu sprechen. Dieser zug beweist aber gar nichts, da jener brief mit zu den bedingungen der wette gehört.

2. Wie George, so weiss auch Pisanio den beweggrund, aus welchem er Imogen ermorden soll. Wie jener, so ist es anch dioser, welcher ant den gedanken kommt, das ungliickliche weib soll manneskleider anlegen und so ihrem tode entgehen.

Diese beiden punkte sind bei Shakespeare eine notwendige folge der damaligen dramatisierung des stoffes. Denn das verhältniss des dieners zu seinem herrn ist in dem drama ein so freundschaftliches, dass letzterer zumal bei einem solch grausamen gebot nicht unterlassen kann den beweggrund desselben Pisanio mitzuteilen. Dass Imogen selbst diesen auffordert sie zu töten, ist ein zug, der zur darlegung ihres charakters und zur verherrlichung ihrer selbst dient. Er ist der erfindung des dichters zuzuschreiben, der sich keine gelegenheit entgehen lïsst, die heldin in ihrer liebe und treue gegen ihren gatten, auf welche das ganze stiuck hinausläuft, zu zeigen. Da aber Imogen ihren tod selbst wünscht, so folgt mit notwendigkeit daraus, dass sie nicht jenen vorschlag zur verkleidung und flucht machen kann.

3. Sowol in der englischen erzählung als auch im drama findet eine schlacht statt, an welcher dort wie hier die gattin in der maske eines pagen teil nimmt. Dort ist sie im dienste Eduard's auf seite der Franzosen, während ihr gatte mit dem übeltäter auf der der Englinder steht. Im drama gehören die entsprechenden personen einer und derselben partei an. Sie werden alle gefangen genommen; in der erzählung trifft dieses loos nur den gatten.

Dieser zug würde entschieden fiur eine benutzung der englischen erzählung sprechen, wenn nicht - wie ich dargelegt habe - Shakespeare das ereigniss einer schlacht bereits in seiner historischen quelle vorgefunden hätte. Dieser kampf und seine ursache, von welcher in der erzählung gar nicht die rede ist, entsprechen sachlich und teilweise auch sprachlich vollständig dem berichte des Holinshed. Eine kampfesschil- 
derung bringt die erzählung nicht, welche auch in sprachlicher hinsicht gar nichts mit dem drama gemein hat. Nach alle dem komme ich zu dem schluss, dass shakespeare auf keinen fall diese englische erzïhlung - selbst wenn dieselbe schon 1603 einmal gedruckt worden wäre - benutzt hat, sondern dass er unabhängig von ihr sein drama nur aus den notizen der chronik und der italienischen norelle mit hilfe seines grossen schöpferischen genius geschaffen hat.' Ich sage 'nur', denn auch die französischen dichtungen fallen - wie ich nunmehr darlegen werde - als quellen fort. Zunächst kommen da zwei altfranzösische romanzen in betracht, von welchen ich wenigstens eine, die mir als die wichtigere erscheint, analysiere. Dieselbe ist betitelt 'Le Roman de la Violette ou de Gérars de Nevers' und hat folgendes zum inhalt.

1 Was die vorlage dieser englischen erzïhlung des fischweibes betrifft, so diirfte manches derselben, mit dem der italienischen novelle verglichen, darauf hinweisen, dass dieselbe die letztere bildet. Dort wie hier ist der held kanfimamn, der in geschätten verreist; dort wie hier trifft er im wirtshaus beim abendbrot kollegen, die iiber die treue ihrer weiber sich unterhalten. Dic personen gehören also auch hier dem bürgerlichen kreise an. Das erzïhlte wird in die zeit Heiurich's VI. gelegt, also in die zeit des krieges zwischen dem hause Lancaster nnd dem hause York. Besonders bietet auch der dialog zwischen den wettenden in der italienischen novelle und dieser englischen erzählung vieles ïhnliche. So z. b. sagt der verfihrer in dieser letzteren: 'Perhaps this woman that you answere for is chaste, but yet against her will: for many women are honest 'cause they have not the meanes, and opportunitie to bee dishonest . had I opportunitie, and knew this same saint you so adore, I would pawne my life and whole estate, in a short while to bring you some manifest token of lier disloyaltie.' Ambrogiuolo iussert: 'Et abbi questo per certo, che colei sola è casta, la quale o non fu mai da alcun pregata, o se pregó non fu esaudita. E dicoti cosi, che se io fossi presso a questa tua cosi santissima donna, io mi crederrei in brieve spazio di tempo recarla a quello che io ho gia dell' altre recate.' Jener gedanke findet sich bei Shakespeare nicht. Ferner wird von Ambrogiuolo erzählt, dass er seine schurkenstreiche ohne das geringste geräusch ausfiihrte 'senza che la donna di niente s'accorgesse.' In der englischen erzählung steht: 'All this performed he with so little noise, that neither the mistriss nor the maid heard him.' Adhnlich ist ferner der inhalt der folgenden stelle in der novelle: 'Quando Bernabó udi questo, parve che gli fosse dato d' un coltello al cucore, si fatto dolore senti', mit der in der englischen erzählung: 'at the sight of this (the crucifix), his bloud left his face, running to comfort his faint heart, which was ready to breake at the sight of the crucifix'. 
Ludwig, könig von Frankreich, veranstaltet an einem ostertag ein grösseres fest, zn welchem er seinen ganzen hof einladet. Einer der gäste, der graf Gérars de Nevers, bekannt und beliebt durch seinen schönen gesang, wird von dem burgrogt von Dijon aufgefordert zu singen. Gérars komut dem wunsche nach und verherrlicht in diesem gesang sein weib Euriant wie folgt:

'Que plus n'ainme que nul rien

Cele de cui me sui vantés,

Qui tant a sens et loiautés'.

Einer der ritter, Lisiard, 'comte et sire de Forez', liält das lob fiir iibertrieben und wettet um sein ganzes land, Euriant innerhalb einer woche \%u verfiihren. Vergeblich sucht der kïnig diese wette zu verhindern. Lisiard begibt sich auf Gérars' schloss und wird anfangs von der gattin gut anfgenommen, aber stolz abgewiesen, sobald er seine gemeine absicht zil erkemnen gegeben. Sie sagt:

'Ha, sire, merchi pour pitié
Se jou or vostre dit endure
Et je ne vous responc laidure.
Sachiez c'est par me courtoisie'.

Durch den gedanken geängstigt dic wette verloren zu haben, zicht er sich zuriick, wird aber bald durch die alte dienerin der gattin, Gondrée, beruhigt. Dieses weib, welches bereits ihre beiden unelielichen kinder, deren vater ein mönch war, getötet hatte, besticht Iisiard, nachdem er es von seiner wette unterrichtet. Daranf gibt sie fihm gelegenheit Euriant durch ein kleines loch der tiire im bade zu sẹen. Es heisst im gedicht:

'La vieille le prent, si l'adréce

Au pértuis qu'elle fait avoit.

Le prince y met son oel et voit

Desor sa destre mamelete

Indoier cele violette'.

Von diesem male weiss nur ihr gatte, welcher sie verlassen will, sobald ein anderer sich ruhme dasselbe gesehen zil haben. Lisiard sicht es. Frfreut kehrt er nach Melun zuriick und erstattet dariiber dem könig und den versammelten gästen bericht. Auch Euriant wird vom könig dazu herbeigerufen. Lisiard erklärt die wette gewonnen zu haben. Als beweis seines erfolges führt er das mal auf Euriant's rechter brust an. Gérars lïsst sich täuschen und ist entschlossen, sein weib aus rache zu töten. Er führt es in einen wald. Aber in demselben augenblick, in welchem er gegen Euriant sein schwert zieht, erblickt dieselbe eine schlange, welche ihres gatten leben bedroht. Sie macht ihn auf die grosse gefahr aufmerksam. Aus dankbarkeit schenkt er ihr das leben und iiberlässt sic ihrem eigenen schicksal. Euriant fällt ohnmächtig zu boden. In diesen zustand findet sie der voriberziehende herzog von Metz und nimmi sich ihrer an. "Gérars dagegen begibt sich, von neugierde getrieben, in das land, das friher sein eigenes war, aber nimmelir im besitz des Lisiard ist. Um nicht erkannt zu werden, verkleidet er sich als minstrel und wird als solcher am hofe gut anfgenommen. Daselbst hat cr gelegenheit Lisiard 
im gespräch mit fondrée zu belauschen, aus welchem er von dem schändlichen betrug kemntniss gewinnt. Sofort verlïsst er Lisiard's hof, um sein unschuldiges weib zu suchen. Auf diesen wanderungen hat er die verschiedensten abenteuer zu bestehen.' Schliesslich triff't er mit mehreren rittern zusammen, welche nach Metz gehen, um der hinrichtung eines weibes beizuwohmen, welches der herzog vor zwei jahren im walde angetroften und mitgenommen hätte. Dasselbe sei angeklagt die schwester des herzogs ermordet zu haben. Gérars erkennt in diesem ungliicklichen weibe das seine und begibt sich sofort nach Metz. Euriant steht vor dem feuer, das sie verbrennen soll, und verrichtet ihr letztes gebet: Gérars bittet den herzog denjenigen herausfordern zu dürfen, welcher das weib irgend eines verbrechens schuldig $z u$ machen wage. Diese bitte wird ihm gewährt. Es meldet sich ein ritter zum zweikampf, fiillt aber und bekennt sterbend, der mörder der schwester des herzogs zu sein. Euriant ist nummehr gerettet und wird dem siegrer, der sich als ihr gatte entdeckt, iibergeben. Dieser reist mit ihr an den hof des Lisiard und zwingt denselben seine schurkerei dem könig zu enthiillen. Lisiard wird mit dem tode bestraft und Gondrée lebendig verbrannt. Gérars nimmt von seinem lande wieder besit\%.

Amaury Duval ${ }^{2}$ behauptet, dass Shakespeare den stoff zu Cymbeline aus dieser romanze genommen habe. Collier ${ }^{3}$ zeigt deren nahe beziehung zu dem englischen drama, erklärt aber nicht, ob Shakespeare sie benutzt habe oder nicht. Simrock führt die ansicht Halliwell's an, dass nämlich sowol diese als auch die andere romanze, der Roman du Comte de Poitiers, nur die volkstiimlichkeit und beliebtheit dieses stoffes beweisen, olme irgend welches licht auf das englische drama zu werfen. Ich teile diese meinung vollständig, denn es muss sich jeder beim durchlesen der beiden französischen romanzen sagen, dass diejenigen punkte, welche das drama mit ihnen gemein hat, auch in der italienischien novelle sich vorfinden. Diese aber laufen auf weiter nichts hinaus als auf die fabel iiberhaupt und das mal im besonderen - welches sich aber hier auf der rechten brust der sehönen befindet --, statt dessen in dem letztgenannten roman ein ring, ein stiick des kleides der gattin und einige (10) ihrer kopfhare zu beweismitteln werden, die ebenfalls wie gold glänzen:

'Vés chi $\mathrm{X}$ de ses chevex sors

Qui plus reliusent que fins ors'.

' Dieselben nelmen einen sehr grossen teil des gedichtes ein. Sie scheint der dichter mit vorliebe zu schildern.

2 'Histoire littéraire de la France' 18.5, bd. 18 s. 769.

3 Shakespeare's Library. Vol. II s. 179-210. 
Im übrigen aber weicht der Roman de la Violette ganz bedeutend von der italienischen novelle und dem drama ab; so in der entdeckung des betruges durch den gatten selbst, der hier als minstrel, im Roman dn comte de Poitiers als pilger erscheint, ferner in den weiteren schicksalen der heldin, die, dort eines mordes angeklagt, zum fenertod verurteilt, aber durch ein gottesgericht freigesprochen wird; hier dagegen, im Roman du comte de Poitiers, soll sie gewaltsam eine ehe mit Harpin eingehen, der sie im walde gefunden und mitgenommen hatte. Dem Roman de la Violette ist auch allein der zug eigen, dass der uilheltäter das mal der gattin durch ein türloch sieht, während sie im bade sitzt. Es ist daher auch nicht das geringste material vorhanden, auf grund desselben man auch nur wahrscheinlich machen könnte, dass Shakespeare diese beiden romanzen gekannt und benutzt hätte. Eine analyse der zweiten romanze zu geben wäre überflüssig, da dieselbe in der hauptsache mit dem Roman de la Violette übereinstimmt. Und es liegt nichts näher als die annahme, dass die eine eine blosse copie der anderen ist. Denn in beiden findet man dasselbe gastmahl des königs; dieselbe verräterei einer weiblichen dienstperson; dieselbe gefahr, welcher der held in dem augenblick ausgesetzt ist, in welchem er sein unschuldiges weib ermorden will; denselben vorfall, dass dasselbe von einem daherziehenden herzog im walde gefunden und mitgenommen wird; denselben weg, auf welchem der gatte zur überzeugung von der unschuld seines weibes gelangt. Ausserdem fuhren die helden denselben namen, Gérars. Welcher von beiden dichtern hat nun das werk des andern copiert? Raynouard in dem 'Journal des Savants' vom jahre 1831 ftihrt auf s. 392 einige punkte an, welche es wahrscheinlich machen, dass Gibert seinen Roman de la Violette vor abfassung des Roman du comte de Poitiers schrieb. Letzterer besteht aus zwei teilen. Der erste hat zum gegenstande was im Roman de la Violette erzählt wird; der zweite hat die abenteuer des Gui zum inhalt, des sohnes des grafen, welcher schliesslich nach Constantinopel kommt, wo er die tochter des verstorbenen kaisers zur frau und dessen reich in besitz nimmt. Dieser teil ist weit besser als der erste, welcher ebenso dem Roman de la Violette an poetischem wert bedeutend nachsteht, und ich kann hier nicht unterlassen die frage aufzuwerfen: Entschloss sich vielleicht 
der dichter, welcher vermutlich die romanze Gibert's hatte vortragen hören und daran gefallen gefunden, dieselbe fortzusetzen, und hielt er es zu diesem zwecke vielleicht für zwekmässig erst das, was er gelört, widerzugeben?

Etwas lïnger als bei diesen romanzen verweile ich bei dem französischen mirakelspiel, da dasselbe noch einige als von Shakespeare benutzt ansehen, so z. b. Simrock und Hertzherg. Folgendes ist sein inhalt.

Kaiser Lothar besiegt den spanischen herrscher Alfons. Dieser flieht zu seinem bruder, dem könig von Granada. Lothar belagert mit scinem neffen Ostes die feste Burgos, in welcher Alfons seine tochter Denise zuriickgelassen hat. Die feste muss sich ergeben und Lothar nimmt das maidchen gefangen, welches er seinem neffen zur gattin gibt. Denselben macht er zum künig von Spamien. Darauf reist Ostes, welcher Denise den nagel einer seiner fusszehen schenkt und sie warnt niemandem das auf ihrer brust sich befindliche mal sehen zu lassen, mit Lothar nach Rom. Die abschiedsworte des gatten sind:
'Je vous pri, dame, çi venez.
Gardez-me cest os-ci tenez,
Si en riens avez chiez m'amistié;
Car c'est d'un des doiz de mon pié.
Et gardez qu'il ne soit véu
Ne de nul homme appercéu
Pour chose nulle, qui aviengue;
Ce sera la secrée enseigne
Que nous y l'un i l'autre avons'.

In Rom trifft Ostes den Grafen Berengier, welcher es für unklug findet, dass Ostes sein schönes, junges weib allein zuriickgelassen hat. Er riihmt sich jedes weib verfihren zu wollen, sobald or gelegenheit gehabt mit ihm zweimal zu sprechen. Und so wettet er, dass er auch Denise fïir sich gewimnen könnte und wiirde. Ostes, dariber sehr gereizt, nimmt die wette an und verlangt von ihm jenen nagel sowie kenntniss von dem male als beweismittel fïr seinen erfolg. Berengier reist nach Burgos. Hier gelingt es ihm zwar mit Denise in's gespräch zu kommen, aber seine versuche sie zu schnöder lust zu gewinnen, scheitern. In voller verzweiflung dariiber macht er das kammermïdchen der schönen gattin Ostes' mit seiner wette bekannt und verheisst ihr eine hohe belohnung, wenn dasselbe ihn einige dinge verschaffe, die seinen erfolg beweisen würden. Das mäidchen gibt der königin einen schlaftrunk und stiehlt den nagel, während sic schläft. Denselben händigt die treulose dem grafen ein und unterrichtet ihn von dem 'secrée enseigne'. Berengier kehrt nach Rom zuriick' und Ostes glaubt auf grund dieser beweismittel dem betriiger. Aus rache will er seine gattin tïten. Von dieser absicht ihres gatten wird sie aber von einem biirger unterrichtet. Darauf bittet sie in der kirche Gott um beistand. Gott ersucht die heilige jungfrau dem ungliicklichen weibe 
hilfe zu bringen. Demselben wird durch die engel Gabriel, Michael und Johannes der rat $\mathrm{zu}$ teil, in der verkleidung eines steward zu ihrem vater und oheim nach Granada zu fliehen. Letzterer nimmt sie, die sich nunmelr Denis nennt, in seine dienste und macht sie zum fähndrich des gegen Lothar aufgestellten heeres. Aber sie möchte einen kampf vereiteln und erhält die erlaubniss nach Rom zu Lothar zu gehen. Auf dieser reise begegnet sie ihrem gatten Ostes, der zu den Sarazenen übergetreten ist, und nun auf den rat jener engel auch nach Rom wandert, um vergebung seiner sünde zu erlangen. Denise erkennt in diesem wanderer ihren gatten und erfährt von ihm die wette, entdeckt sich ihm aber nicht. Dies tut sie in Rom, nachdem sie den grafen Berengier der verleumdung bei dem kaiser Lothar angeklagt hat. Ostes fordert den grafen zum zweikampfe. Berengier fällt und berichtet noch sterbend alle einzelheiten seiner schurkerei. Darauf sendet Denise nach ihrem vater und oheim. Alfons verzichtet auf sein königreich, welches Ostes erhält und bekommt dafiir das königreich Mirabel.

Dieses mirakelspiel stimmt wie die tibrigen hierher gehörigen dichtungen mit dem englischen drama in der hauptfabel im grossen und ganzen überein, steht aber diesem als mittelalterliches drama natiirlich weit nach. Entwickelung der handlung aus den charakteren der einzelnen personen zeigt es sehr wenig. Der dialog herrscht vor, die eigentliche handlung tritt zuriek. Wahrhafte poesie geht ihm ab: das geschehene wird kurz und niichtern erriahlt: Die wenigen bilder, welche der dichter gebraucht, sind zum teil unschön; so z. b. das, welches Berengier gebraucht, um die treulosigkeit und geringschätzung zu charakterisieren, mit welcher Ostes in seiner abwesenheit Denise behandele; er sagt zu dieser:

'De Romme vien où j'ay laissié

Vostre seigneur, qui ne vous prise

Pas la quene d'unc serise'.

Niichtern und übertrieben ist die stelle, wo der graf, von Denise abgewiesen, derselben seine liebe erklïrt:

'Pour vostre amour palis et tain

Souvent et ay cuer esperdu,

Si que j'en ay du tout perdu

Boire et mengier'.

Unnschön ist ferner das geschenk, welches Ostes bei seinem abschied seinem weibe gibt. Sehr unzart ist auch der zug; dass Denise bei enthüllung ihrer maske zum beweis ihres geschlechts zu den versammelten folgendes sagt:

'Ne cuidez pas que devine;

Tenez, regardez ma poitrine:

G'y ay mamelle comme fame; 
Dul monstrer n'est point de diffame.

I.es autres membres secrez tous

Feminins ay, ce savez-yous'.

Charakteristisch für das ganze stïck sowie besonders für die motivierung der einzelnen handlungon sind folgende stellen. Um dem grafen Berengier zu seinem zwecke zu verhelfen, beabsichtigt Esglantine, die dienerin der jungen königin, derselben einen solchen wein zu reichen, der sie trunken mache und zum schlafen bringe. Ist dies eingetreten, so will sie ihre herrin des geschenkes berauben und nach dem merkmal ihres körpers suchen. Unmittelbar darauf, nachdem Esglantine ihren plan uns mitgeteilt hat, tritt Denise auf und verlangt wein und äpfel, denn sie habe grossen durst. Die betreffenden stellen sind:

La. Démoisselle (Esglantine)

'Hé je scé bien que je feray:

A ma dame boire donray

Encore ennuit un vin si fait

Que pourray veoir tout-i-fait

Son corps partout, quant dormira,

Que jà ne s'en esveillera

Pour remurer ne pour tourner.'

La Fille (Denise)

'Esglantine, sachés que j'ay

Fain de boire trop malement.

Alez me querre appertement

Des pommes et du vin aussi,

lit si le m'aportez icy

'I'ost, je vous pri.'

Als Esglantine den wein gebracht hat, sagt sie /u ihr:

'Verse, verse, a boire me doune:

J'ay soif trop grant.

Si grant soif n'oy pieça, par m'æme!

Comme ore avoie'.

Esglantine möchte ihr noch mehr reichen, doch sie entgegnet:

'Nanil pas; mais aler voulray

Reposer; car en vérité,

Ce vin m'est jà on chief montè

Ce in'est avis'.

Eine dieser scene ähnliche findet sich im weiteren verlaufe des stiickes. Als Denise bei ihrem vater und oheim in Granada als truchsess (écuyer) verkleidet in den dienst treten will, wird sie von beiden gewissermassen gepriift. Dieses examen wird 
dadurch herbeigefiihrt, dass der könig von Granada plötzlich hunger bekommt. Er sagt zu seinem bruder Alfons:

'Frere, j'ay trop bon appetit

De mengier envoions-ent querre

Par cest escuier-ci bonne erre.

Aussi desiré-je la ğuise

Moult regarder de son servise

Je vous dy bien'.

Alfons spricht darauf zu Denise:

'Denis, dressiez appertement

Une table ci, sauz songier,

Et nous alez querre $i$ mengier

En la cuisine'.

Diese stelle zeigt in ihrem weiteren verlaufe recht dentlich die nahe beziehung zu der italienischen novelle. Wie hier Denise, so tritt auch dort Ginevra' bei dem sultan auf; wie der könig von Granada und Alfons an den bewegungen und dem ganzen benehmen der Denise gefallen finden, so auch der sultan an dem Ginevra's, und wie in folge dessen jene Denise zum fahnenträger (gonfanonnier) ernennen, so erwählt dieser Ginevra zum hauptmann.

In einer solch niichternen und kurzen weise, in welcher die bis jetzt citierten stellen dem leser entgegentreten, ist zum grössten teil das ganze stiick gehalten. Nur da, wo es die situation mit notwendigkeit verlangt, wird der dichter etwas lebhafter und zeigt, dass er nicht gïnzlich poesielos ist. Wie kurz und einfach aber auch diese stellen sind, beweisen z. b. die worte des königs Ostes, welche er dem grafen Berengier sagt, als dieser ihm die beweise fiur seinen erfolg gebracht:

'E, diex! com je sui adolez;

Je voy bien j'ay perdu ma terre.

Le cuer d'ire ou ventre me serre.

Darauf g'eht der graf ab, wie aus der interpunktion ersichtlich ist, und Ostes fährt fort:

'Ha, très faulse et deloyal femme!

Comment m'as-tu fait tel diffame?

Voir, en ta bonté me fioie

1 Lobt ja dort auch Bernabo seine gattin in dieser beziehung. Er sagt: 'Oltre a questo niuno scudiere, o famigliar che dir vogliamo, diceva trovarsi, il quale meglio è più accortamente servisse ad una tavola d'un signore, che serviva ella'. 
Tant qüa la meilleur te tenoie

Des femmes; mais ne fineray

Jamais tant qu'à mort nis t'aray

Honteusement'.

Wie schwach ist diese stelle im vergleich zu der 4 . und 5. scene des II. aktes vou Cymbeline. Hier im mirakelspiel spricht der von Berengier betrogene gatte keinen weiteren gedanken aus als den, dass er sich in seinem weibe getäuscht hat und sie wegen ihrer treulosigkeit um's leben bringen will. Posthumus dagegen verlangt erst die einzelnsten angaben, ehe er dem verräter glauben schenkt. Als er sich aber von dem treubruch seiner gattin iiberzengt glaubt, giebt er seinem schmerze in einer weise ausdruck, die nur Shakespeare eigen ist. Welche gedankenfiille enthält der monolog des Posthumus, welche umwälzung bringt die verläumderische tat Jachimo's in der denkweise des gatten über die frauenwelt hervor! Und wie naturgemäss sind die ausbriche seines zornes und seiner rache!

In demselben verhältniss wie diese scéne im mirakelspiel zu den beideǹ letzgenaunten im englischen drama, steht das ganze mittelalterliche drama zu dem englischen. Es trägt im vergleich zu diesem mehr das gepräge einer inhaltsangabe, die vorgänge werden in der kürzesten und lockersten weise an einander gereiht. Eng damit in beziehung steht die ausserordentlich schwache und mangelhafte zeichnung der charaktere, in welcher Shakespeare meister ist. Von einer benutzung etwaiger charakterzitge von seiten des englischen dichters kann nicht die rede sein. Es liisst sich nicht ein einziger zug darin finden, den sich Shakespeare speciell zu eigen gemacht. Ich hebe dies hier ausdrticklich hervor, weil gerade Shakespeare, wenn er benutzte, sich stets feine zitge, die zur belebung und zur steigerung der naturwahrheit dienen konnten, unbedenklich zu eigen machte. Von dieser art der entlehnung sehe ich aber hier keine spur. In dem grade, in welchem die einzelnen personen in dem mittelalterlichen drama charakterisiert sind, sind sie es auch in der italienischen novelle. Dort fand Shakespeare den ganzen inhalt des stückes, dort fand er auch die grundziige der charaktere, wie sie sich notwendig aus dem stoff ergeben. Das französische mirakelspiel zeigt gerade, was charakterzeichnung betrifft, noch zu sehr die erste stufe des dramas. Dafür spricht auch das auftreten Gottes, der heiligen 
Maria und der engel Gabriel, Michael und Johannes. Hierher gehört auch die stelle, wo Gott den könig Ostes auffordert seine sünde, von ihm abgefallen zu sein, zu bereuen und in Rom busse zu tun. Ausserdem finden sich in diesen scenen auch lobgesänge der engel (rondels) auf die heilige Maria. Ich habe dies hier erwähnt, weil man mit diesem dem charakter eines mirakelspiels eigentümlichen zug vielleicht die erscheinung jener geister und des gottes Jupiter in der kerkerscene (V 4) des englischen dramas in beziehung bringen könnte. Dort erscheinen dem schlafenden als kriegsgefangener gefesselten Posthumus die geister seiner ältern nnd briider und bitten Jupiter unter der drohung bei nichterfuillung ihrer bitte von ihm ahzufallen, ihrem ungliicklichen sohne und bruder zu helfen. Darauf erscheint Jupiter mit donner und blitz und zürnt den geistern irdischer abkunft ob ihres unwillens, verheisst aber dem schlafenden freude und gliick fiir die ertragung seines geschickes. Er legt ihm sein zukiinftiges loos auf eine tafel geschrieben auf die brust und verschwindet. Die geister danken und folgen ihm. Posthumus aber erwacht aus seinem schlafe; das, was der dichter wïhrend desselben vorfuihrt, hat der gefangene geträumt. Er findet die tafel und liest jene prophezeihung, mit deren erfüllung und deutung durch einen wahrsager das stiick endet.

Diese scene ist jedoch von der aus dem mirakelspiel erwähnten vollständig fern zu halten; denn sie ist ganz anderer natur und hat einen andern zweck als diese. In dem mittelalterlichen drama gehört sie mit notwendigkeit zur entwicklung. des sttlckes, in dem englischen dagegen ist sie ein selır unwesentlicher bestandteil, der vom dichter auch hïtte weggelassen werden können, ohne die entwicklung der handlung im geringsten zu stören. Sie ist von Shakespeare selbst geschaffen, bei dem ja ïberdies geistererscheinungen nichts ungewöhnliches sind. Derartige scenen sind unter dem namen 'Masques' nur allzusehr bekannt, ich erinnere z. b. an die im 'Sturm'.

Nachdem ich das französische mirakelspiel im vergleich zu dem englischen drama ganz im allgemeinen charakterisiert habe, gehe ich nun zu den einzelnen stellen und ziigen über; auf grund deren die vermutung wach gerufen wurde, dass Shakespeare dieses mittelalterliche drama benutzt habe. $\mathrm{Zu}$ nächst gehört hierher folgender auftritt: 
Berengier sagt zu Ostes:

'Et vous dy bien que je me rant

Que je ne sçay femme vivant

Mais que ij foiz à li parlasse

Que la tieree aroiz n'en cuidasse

'Tout mon relit'.

Jachimo behauptet gegen Posthumus (I, 5):

'I will lay you ten thousands Duckets to your Ring, that commend me to the Court where your Lady is, with no more aduantage then the opportunitic of a second conference, and I will bring from thence, that Honor of hers, which you imagine so reseru'd'.

Dieser darin iibereinstimmende zug, dass der verfiihrer die junge gattin nach zwei maligem gespräch für seinen gemeinen sweck zu gewinnen behauptet, ist ein rein zufälliger und als. solcher ganz untergeordneter art. Dass beide nicht äusseru, ihre absicht gleich bei der ersten begegnung zu erreichen, ist vorsicht von ihnen und als solche sehr natiurlich. Ausserdem aber sagt Jachimo kurz vor jenen worten zu Posthumus:

'With fiue times so much conuersation, I should get ground of your fair Mistris: make her go backe, euen to the yeilding, had I admittance, and opportunitie to friend'.

Auch diese worte beweisen, dass an eine entlelnung des obigen zuges aus dem mirakelspiel nicht zu denken ist. Dasselbe liisst sich auch von der folgenden stelle behaupten. Sie betrifft die art und weise des verführungsversuches. Berengier wie Jachimo suchen zunaichst in den jungen frauen. eifersucht zu wecken und zwar dadurch, dass sie ihre gatten der stärksten untreue beschuldigen. Die betr. verse im mirakelspiel lauten:

'Ma dame, je le vous diray:

De fait me sui cy adressié.

De Romme vien, où j'ay laissié

Vostre seigneur, qui ne vous prise

Par la queue d'une serise;

D'une garce c'est acointié

Qu'il a en si grant amistić

Qu'il ne scet de elle departir.

Ce m'a fait de Romme partir

Pour le vous annuncier et dire,

Car grant dueil en ay et grant ire;

Er pour ce qu'ainsi a mespris,

I'amour de vous m'a si espris

Que nuit ne jour ne puis durer:

'Tant me fait griefs manlx endurer

Pour vous, ma dame!' 
Ganz ähnliches sagt Jachimo zu Imogen, akt I, scene VII. Vergleicht man diese scene mit obiger stelle, so findet man weiter nichts gleiches darin, als dass beide verführer die gatten der jungen weiber der buhlerschaft mit frechen dirnen beschuldigen, uiber ein solches betragen unwillen heucheln und ihnen gleichsam als entschädigung für die ihnen angetane schmach ihre liebe erklären.

Dieser zug, der sich wie der vorige in keiner anderen der hierher gehörigen dichtungen findet, ist aber bei weitem nicht der art, dass er eine benutzung des mirakelspiels von seiten Shakespeare's beweist, und schon Delius bemerkt sehr richtig, dass er ebenso gut von dem grossen Briten als von dem dichter des mittelalterlichen dramas erfunden werden konnte. Dass dieser zug wirklich aus Shakespeare's geiste entsprossen ist, zeigt der aufbau dieser ganzen scene. Der verführungsversuch des Jachimo ist ein weit feinerer, mehr durchdachter und ausführlicherer als der des Berengier. Diese scene steht eben als teil in demselben verhältniss zu der entsprechenden des mirakelstiickes als das ganze zum ganzeu. Hier gerade hat Shakespeare den Jachimo in einer weise charakterisiert, wie sie dem französischen stücke gänzlich abgeht. Nachdem Jachimo der Imogen den brief ihres gatten übergeben, bewundert er ihre schönheit. Er glaubt, dass er seine wette verlieren werde, wenn das junge weib ebeuso tugendhaft sei als sie schön ist. Seine worte sind:

\footnotetext{
'All of her, that is out of doore, most rich:

If she be furnish'd with a mind so rare,

She is alone th' Arabian-hird, and I

Hane lost the wager!'
}

Sie liest den brief, dankt dem überbringer und heisst diesen willkommen. Jachimo dankt desgleichen für den freundlichen empfang und ergeht sich darauf in einer ihr undeutlichen rede uiber den umstand, dass das auge der menschen, welches die sterne am himmel und die steine am meeresstrande unterscheiden, obwol sich diese wie zwillinge glichen, doch keinen unterschied zwischen schön und hässlich machen könnte. Er zielt eben auf Posthumus, von dem er später erzählt, dass derselbe in Rom mit schmutzigen gemeinen dirnen buhle, während er zu hause eine so schöne gattin zu eigen habe. Imogen's frage: 'What makes your adimiration' lässt er ganz unberührt, und um ihre neugierde 
noch mehr zu erregen, fuihrt er in seiner rede fort. Er sucht den grund jenes umstandes und findet denselben schliesslich in

'The Cloyed will:

That satiate yet vnsatisfi'd desire, that Tub

Both fill'd and ruming: Ranening first the Lambe,

Longs after for the Garbage'.

Imogen glaubt, er ist unwol - denn ihr sind solche dinge unverständlich. Er verneint dies und beginnt, nachdem er seinen diener entlassen, das vorher gesagte auf Posthumus anzuwenden. Jachimo geht dabei mit sehr grosser vorsicht zu werke. Zu statten kommt ihm die frage Imogen's, ob ihr gatte in Rom $z u$ heiterkeit aufgelegt sei. Er antwortet ihr:

(He is) 'Exceeding pleasant: none a stranger there,

So merry, and so gamesome: he is call'd

The Britaine Reueller.

I neuer saw him sad.

There is a Frenchman his Companion, one

An eminent Monsieur, that, it seemes, much lones

A Galliam-Girle at home. He furnaces

The thicke sighes from him, whiles the iolly Britaine,

(Your Lord I meane) laughes from's free lungs: cries oh,

Can my sides hold, to think that man who knowes

By History, Report, or his owne proofe,

What woman is, yea what she cannot choose

But must be: will 's tree houres languish:

For assured bondage?'

Diese zeilen eröffnen uns den charakter Jachimo's recht deutlich. Er, der in Rom über die feste uberzeugung des Posthumus von der treue und liebe seines weibes gespottet, beschuldigt jetzt ihn dieser schlechten meinung tiber frauentreue. Darauf heuchelt er mitleid mit ihr. Dies reizt die neugierde des schönen weibes von neuem: sie will wissen, warum er sie bemitleide. Aber noch hält er mit seiner verleumderischen rede zurück, geschickt weiss er Imogen auf das folgende ïusserst gespannt zu machen. Sie sagt zu ihm:

'pray you,

Since doubting things go ill, often hurts more

Then to be sure they do. For Certainties

Either are past remedies, or timely knowing,

The remedy then borne. Discouer to me

What both you spur and stop'.

Aber auch hier erfillt er ihre bitte noch nicht; er strebt dahin, dass Inogen selbst auf den gedanken kommt, welchen er noch 
nicht auszusprechen wagt. Dies erreicht er dadurch, dass er vorgibt, er wirde nie im stande sein mit anderen und zwar gemeinen, frechen dirnen umgang zu pflegen, wenn er ein so schönes weib, wie Imogen, besïsse. Darauf nun vermutet sie, dass Posthumus Britanien vergessen habe, - und Jachimo hat den gewünschten anknïpfungspunkt gefunden. Nummehr beschuldigt er ihren treuen gatten eines sehr schlechten lebenswandels, nennt sie, die sie einem trone nahe stehe, rivalin frecher dirnen, feiler metzen, und fordert sie auf zur rache. Er sagt:

'Be reineng'd,

Or she that bore you, was no Queene, and you

Recoyle from your great Stocke'.

Dadurch glault er seiner absicht nahe gekommen zu sein. Denn als sie ihm daranf erwidert, dass sie nicht wisse, wie sie sich rïichen könnte, teilt er ihr die mittel und wege dazn mit und bietet ihr seine dienste an:

'I dedicate my selfe to your sweet pleasure,

More Noble then that munagate to your bed,

And will, continue fast to your Affection,

Still close, as sure'.

Imogen sieht nunmehr klar, warum Jachimo zu ihr gekommen ist und ihren gatten so arg verleumdet hat. Sie weist ihn kithn und standhaft zurtuck und droht ihm ihren vater, den könig, von diesem frechen angriff in kenntniss zu setzen. Er aber bittet jetzt demitiglichst um verzeihung und gibt vor dies nur deshalb gesagt zu haben, um die stärke ihrer treue und liebe $\%$ ihrem gatten $z u$ prüfen, den er jetzt der wahrheit gemäss in dem glänzendsten lichte darstellt. Imogen vergibt itw seine handlungsweise und verspricht nunmehr das vorgebliche geschenk in verwahrung nehmen zu wollen, welches er mit Posthumus für den könig gekauft habe.

Diese ganze scene findet sich in dern mirakelspiel in folgender weise. Berengier begriisst Denise:

'Chiere dame,

Longue vie et salut de l'ame

Dieu vous ottroit'.

Sie fragt ihn sofort nach dem grunde seines besuches:

'Qui vous maine par' ci endroit,

Berengier? Bien vegniez, bian sire.

Si le vous plaist a le moy dire,

Je vous urray'. 
Darauf gibt ihr Berengier das auf s. 29- citierte zur antwort. Denise erkennt daraus seine absicht, sie nennt ihn und seinen ganzen stamm verleumder und verräter, und gebietet ihm, sofort sich $\mathrm{zu}$ entfernen:

'Comment, Berengier? Par vostre ame!

Estes-vous un si vaillant homme

Que venez jusques cy de Rome

Pour moy dire si fait langage?

Certes vous ne vostre lignage

Ne saviez dire un seul bien non,

Fors mauvaistié et traïson;

Et pour ce de rien ne vous croy.

Vuidiez, vuidiez de devant moy.

Isnel le pas'.

Auch die nochmalige beteuerung seiner liebe $\mathrm{zu}$ ihr und das versprechen solches von ihrem gatten nie wider zu sagen, können Denise nicht anders stimmen: sie zieht sich mit Esglantine in ihr gemach zurtick.

Vergleicht man diese scene mit der entsprechenden des englischen dramas, so bedarf es, wie schon gesagt, keines näheren beweises dafiir, dass Shakespeare sich von dem im mirakelspiel gesagten in keiner weise hat beeinflussen lassen. In der ganzen entwicklung und dem aufbau der rede Jachimo's erkennt man sofort den freischaffenden genius des dichters.

Hertzberg - und ihm schliesst sich auch Simrock an ist auf grund folgender ztige sehr geneigt anzunehmen, dass Shakespeare das mittelalterliche drama gekannt und benutzt habe:

1. Der unstand, dass in dem englischen drama wie in dem altfranzüsischen stiick eine kriegsaction zum hintergrund des ganzen gemacht, und Rom in die handlung mit hineingezogen sei. - Nach meiner ansicht fällt aber hier jegliches bedenken fort, wenn man sich daran erinnert, dass der britische dichter - wie ich ansfiuhrlich dargelegt habe - sowol den anlass zu diesem kampfe als auch diesen selbst sehr ausfihrlich bereits in der chronik Holinshed's vorfand. Von einer motivierung des kampfes ist aber im mirakelspiel nicht die rede, desgleichen mangelt es ihm an einer kampfesschilderung. Dic ciunahme von Burgos ist sehr mangelhaft dargestellt und zu einem wirklichen kampfe kommt es gar nicht; denn dieser wird durch Denise verhindert. Dass Posthumus nach Rom in die verbannung geht, wird deshalb notwendig, weil sonst die zahl der orte der handlung eine zu grosse werden würde. Fand doch Shakespeare Rom als ort der handlung auch schon in der erwïhnten chronik vor. Ausserdem aber hatte Shakespeare geplant den helden im kampfe als Römer auftreten zu lassen und als gefangenen Cymbeline's zu zeigen.

Anglia, VI. band. 
2. Der zug, dass Denise wie Imogen während sic schläft, bestohlen wird. - Auch dies beweist fuir eine benutzung des mirakelspiels gar nichts. Denn hier gerade zeigt sich bei Shakespeare die engste anlehnung an die novelle des Boccaccio, wo ja Ambroginolo ganz anf dieselbe weise \%u den seinen erfolg beweisenden gegenstäinden gelangt als Jachimo. Jene kiste kennt, gleichwie 'Westward for Smelts' - das mirakelspiel nicht.

Der 3. punkt endlich, anf welchen Hertzberg seine ansicht stiitzt, dass Denise durch Esglantine mittelst eines besonderen weines tminken gemacht und zum schlafen gebracht wird, - lat mit dem schlafpulver, welches Imogen als herzstïrkendes mittel erlüilt, durchaus nichts gemein. Es hat einen ganz anderen zweck als jener wein: Imogen soll dadurch ihres lebens beraubt werden. Ich werde in dem folgenden teil ansfiilirlicher darauf zuriick kommen.

Ebenso wie inhaltlich lässt sich auch sprachlich nichts finden, was auch nur die geringste anlehnung an dieses stick bestätigen könnte.

Fragt man nach diesen erörterungen, was das drama Cymbeline mit dem französischen mirakelspiel in der weise gemein habe, dass eine benutzung des letzteren von seiten Shakespeare's fest zu stellen sei, so ist mit sicherheit zu antworten, dass sich weder in der ganzen entwicklung des stiickes noch in den einzelnen charakteren etwas derartiges finden lïsst. Was beide stïcke speciell gemeinsam haben, ist von mir erwähnt, und dass dies nicht so gewichtig ist, dass darans eine benutzung des mittelalterlichen dramas hervorgeht, habe ich, wie ich glaube, genügend dargetan.

Es bleibt mir nunmehr noch ibbrig die beziehungen in betracht zu ziehen, in welche man ein deutsches märchen zu dem englischen drama gebracht hat. Auf seite 458-60 des IX. bandes der Germania von Pfeiffer glaubt Karl Schenkl bewiesen zu haben, dass Shakespeare zu mehreren scenen des III. und IV. aktes seines dramas das märchen von Sneewitchen benutzt habe. Er stellt dasselbe als dritte sichere quelle für Cymbeline auf. Die züge, welche ihn zu diesem ergebnis gefuhrt haben, sind folgende:

1. Im märchen wie im drama begegnet dem leser eine büse künigin, welche ihre stieftochter hasst und diese um's leben zu bringen beabsichtigt.

2. Die ähnlichkeit zwischen dem aufenthalt Imogen's in der höhle des Belarins und deni Sneewitchen's bei den zwergen:

Wie nämlich diese, so entgeht anch jene in folge ihrer schünheir und unschuld ihrem tod; wie Sneewitchen bei den zwergen, so erfrischt sich auch Imogen in der höhle durch speise und trank. Wie die zwerge Sneewitchen fïr cin himmlisches wesen halten, so auch Guiderius und Arviragus 
die Imogen. Wie Sneewitchen als haushälterin von den zwergen gelobt wird, so riihmen auch die jägerslente Imogen wegen ihrer kochkunst. Guiderius sagt $(I V, 2)$ :

'But his neate Cookerie!

He cut our Rootes in Characters.

And sawc 'st our Brothes, as Juno had biu sicke

And he her Dieter'.

Wie Sneewitchen so ist auch Imógen scheintot, aber weder jene, noch diese hat an schönheit dadurch verloren. Von jener wird erzählt, dass sie wie ein im schlafe lächelndes kind von den zwergen angetroffen worden sei, von dieser sagt Arviragus:

'Starke, as you see:

Thus smiling, as some Fly had tickled slumber,

Not as deaths dart, being laugh'd at; his right Cheeke

Reposing on a Cushion'.

Unter den zwergen herrscht grosse trauer über den tod des schönen kindes; auch die briider beklagen den verlust des herrlichen knaben. Wie jene so wollen auch diese den leichnam nicht in die schwarze erde versenken. Die zwerge betten Sneewittchen in einen krystallsarg und setzen es auf einem berge aus; die jägersleute legen Imogen an die seite der leiche Cloten's und bedecken sie mit blumen. Wie in dem märchen erzählt wird, dass sich auf jenem berge vögel versammelt hätten, um an der seite Sneewittchen's zu weinen und zu klagen, so heisst es bei Shakespeare:

'The Raddocke would

With Charitable bill (Oh bill sore shaming

Those rich-left-heyres that let their Fathers lye.

Without a Monument!) bring thee all this [die blumen],

Yea, and furr'd Mosse besides. When Flowres are none

To winter-ground thy Coarse'.

Diese ubereinstimmenden, von Schenkl angefuhrten punkte zwischen dem drama und diesem märchen können in der tat die ansicht wachrufen, dass dasselbe auf Shakespeare von einfluss gewesen, sobald man, wie Schenkl getan, diese ztige aus dem drama herausschält und sie ohne jegliche verbindung mit dem, was ihnen vorhergeht und folgt, seiner untersuchung unterwirft. Aber man wird ein ganz anderes resultat als das Schenkl's erzielen, wenn man die erwähnten punkte im engsten zusammenhang mit der ganzen handlung des dramas betrachtet und die dramatische entwicklung desselben genau verfolgt. Dieser weg ist nach meiner ansicht auch der allein richtige; würde man demjenigen folgen, welchen Schenkl eingeschlagen, so liesse dies den faden der ganzen handlung des stickes zerschneiden, und loffentlich gelingt es mir dem leser zu 
zeigen, dass ein solches verfahren meist zu einer falschen ansicht fuhrt.

Was den unter 1. angeführten zug betrifft, so gibt Schenkl selbst an, dass derselbe durchaus nichts beweist. Denn der hass einer bösen stiefmutter geg'en ihr stiefkind ist eine im leben sehr allgemeine tatsache, die in vielen erzählungen und dichtungen ${ }^{1}$ alter und neuex zeit eine nicht unbedeutende rolle spielt. Doch selbst wenn man dies ausser betracht stellt, ist gar kein grund vorhanden, welcher auf eine entlehnung dieses zuges im drama aus dem märchen schliessen lässt. Denn die ursache des hasses der königin bei Shakespeare ist eine ganz andere, als die in dem märchen. Imogen ist bei ihrer stiefmutter deshalb in ungnade gefallen, weil sie sich weigert, deren wirklichen sohn Cloten zu heiraten, während Sneewitchen von ihrer stiefmutter deshalb verfolgt wird, weil es dieselbe an schönheit uibertrifft. Man sieht daraus, dass der zorn der königin bei Shakespeare, welcher sofort verschwände, wenn Imogen deren wunsch erfüllen würde, ein weit berechtigterer und natirlicherer ist, als der unwille der königin im deutschen märchen. Die gattin Cymbeline's wird als schlaue teufelin hingestellt, welche unaufhörlich neue ränke schmiedet. Sie ist voll von heuchelei; ehrgeiz und herrschsucht sind die trieb-

1 Siehe z. b. Percy: 'Reliques of Ancient English Poetry', London 1845 s. 234, eine ballade, betitelt: 'The Iady Isabella's Tragedy, or the Stepmother's Cruelty: being a relation of a lamentable and cruel murther, committed on the body of the Lady Isabella, the only daughter of a noble Dnke etc.' Von diesem herzog heisst es:

'This lord he had a daughter deare,

Whose beauty shone so bright, She was belov'd, both far and neare, Of many a lord and knight.

Fair Isabella was she call'd, A creature faire was shee; She was her fathers only joye;

As you shall after see.

Therefore her cruel step-mother

Did enoye her so much,

That daye by daye she sought her life,

Her malice it was such'. etc.

Auf befehl dieses weibes wird Isabella rom koch geschlachtet und dem herzog, ihrem vater, als pastete vorgesetyt. 
federn ihrer schlechtigkeit; ihr einziger wunseh jst zu regieren. Ihr sohn ist das notwendige mittel, durch welches sie dieses ziel zu erreichen sucht. Sie will Cloten mit Imogen, der einzigen erbin des königreichs, verheiraten, um ihm die tronfolge und sich die regierung $z u$ verschaffen. Sie nimmt keinen anstoss an dem gedanken ihren gatten durch gift aus dem wege zu räumen. Aber bald von der fertigkeit des bundes zwischen Imogen und Leonatus Posthumus überzeugt, kann sie nur durch deren tod zu ihrem ziele gelangen. Aus diesen andeutungen wird es jedem einleuchten, dass dieser hass der königin im plane des ganzen stiickes liegt. Imogen verschuldet ihn zum grössten teil, wälırend Sneewittchen furr ihre schönheit nicht verantwortlich gemacht werden kann. Ausserdem ist die art und weise, auf welche die königin im märchen ihr stiefkind zu vergiften sucht, eine sehr verschiedene von der im drama. Bekanntlich verkleidet sich in diesem märchen die böse stiefmutter einmal als händlerin und zum andern mal als bäuerin nnd begibt sich in die huttte der zwerge, wo, wie sie durch ihren spiegel erfahren, Sneewittchen lebt, um diesem das vergiftete band, den kamm und apfel selbst zu reichen. Im drama dagegen beabșichtigt die gattin Cymbeline's zunächst nicht-Imogen, sondern Pisanio zu beseitigen, weil dieser Cloten hasst und ihrem plane hinderlich sein könnte. Sie weiss, dass er den vermittler zwischen ihrer stieftochter und dem in der verbannung lebenden Posthumus spielt und glaubt, dass Imogen, sobald durch den tod des treuen dieners jegliche verbindung. zwischen ihr und ihrem gatten aufhört, denselben aufgeben werde. Nur dann, wenn dies nicht geschieht, will die königin dem leben Imogen's durch dasselbe gift ein ende machen, an welchem Pisanio sterben soll. Als sie diesem dasselbe als herzstärkende arznei verabreicht, sagt sie von $\operatorname{ihm~}(I, 6)$

'A slye, and constant knaue,

Not to be shak'd': the Agent for his Master,

And the Remembrancer of her, to hold

The hand-fast to her Lord. - I haue giuen him that, Which if he take, shall quite vnpeople her

1 Anfungs hat sie versucht durch versprechungen Pisanio zu verleiten, dass er Imogen zur vermählung mit Cloten berede, aber aus seinem darauf erfolgten schweigen schliesst sie, dass er nicht zu diesem zwecke zu erkaufen ist. 
Of Leidgers for her Sweete: and which, she after

Except she bend her humor, shall be assur'd

To taste of too'.

Die königin beabsichtigt durchaus nicht, dass Pisanio die giftigen kräuter ihrer-stieftochter geben soll, wol aber glaubt sie, als beide vom hofe entflohen sind und ihr aufenthaltsort nicht entdeckt wird, dass auch Imogen von dem gifte genossen und dadurch ihren tod gefunden habe. Es ist daher kein zweifel, dass Shakespeare zu diesem punkte kein vorbild in dem deutschen märchen gehabt, sondern diesen selbst geschaffen hat.

Dasselbe gilt auch von den hier unter 2. aufgezählten zuigen Schenkl's. Auch diese gehen mit notwendigkeit aus der dramatischen entwicklung des ganzen hervor. Vor allen dingen muss man immer im auge behalten, dass in dem drama zwei von einander ganz verschiedene erzählungen neben einander herlaufen, welche der dichter vereinigen musste, sobald er einheit der handlung erzielen und bewahren wollte. Ritcksichtlich dieser verbindung der beiden erzählungen sind nur zwei möglichkeiten denkbar. Entweder ist sie von Shakespeare selbst herbeigefuhit, oder von ihm schon in irgend einem poetischen oder prosawerke vorgefunden worden. Aber ein solehes ist bis jetzt noch vollst:indig unbekannt. Man könnte daher vermuten, dass es verloren gegangen sei. Allein wenn man bedenkt, dass diese art der verschmelzung, wie man sie bei Shakespeare findet, nur einem der besseren dichter möglich gewesen wäre, und weiter in betracht zieht, dass heutzutage fast alle werke dieser dichter bekannt und wenn nicht uberliefert, so doch irgendwie erwühnt sind, so würde es doch seltsam sein, wenn man von einem solchen werke nichts witsste, welches, einen für das mittelalter so interessanten stoff mit der erzählung von Cymbeline und seinen beiden, söhnen vereinigt, selbt wenn es verloren gegangen wäre. Und da es ausserdem bekannt ist, dass sich Shakespeare in mehreren seiner dramen (z. b. Lear) von anderen dramatikern gerade dadurch unterscheidet, dass er zwei von einander ganz verschiedene erzählungen vereinigt und dramatisch durchftihrt was ihm wol von manchem mit unrecht zum vorwurf gemacht worden ist und wird - , ist es dann nicht wahrscheinlicher, dass auch diese combination seiner fantasie entsprungen sei? 
Ich bin der ansicht, dass die geschichte von der heimlichen entfuihrung der beiden prinzen durch Belarius und ihrem leben in jenen bewaldeten bergen nur von Shakespeare erdichtet worden sein kann, zumal eben weder Holinshed in seiner chronik etwas davon erwähnt, noch irgend eine andere quelle dafür nachgewiesen ist, vielleicht auch nicht nachgewiesen werden kann. Nun aber könnte es sonderbar erscheinen, dass der grosse dramatiker diese prinzen als einfache jägersleute in einer so wilden gegend vorführt. Der grund hierftir ist kein anderer als der, dass Shakespeare das schlichte und ruhige leben biederer, wahrheitsliebender und von den schäden der feinen gesellschaft in den stiidten freier leute im gegensatz zu den ränken und gemeinen handlungen an den höfen zeigen will, welche dem hofe Cymbeline's an die seite zu stellen sind. Belarius hat das intriguante treiben dieses hofes zur gentige kennen gelernt. Als die beiden prinzen noch klein waren, lebte er, ein treuer und tapferer krieger, an Cymbeline's hof. Plötzlich fiel er bei dem könig in ungnade. Zwei schurken hatten ihn verleumdet und beschuldigt in verraterischem bunde mit den Römern gestanden zu haben. Der könig verbannte. ihn deshalb und beraubte ihn seiner besitzungen. Aber der wackere soldat war unschuldig und rächte sich an Cymbeline dadurch, dass er dessen beide söhne mit ihrer amme in jene berge entfihite. Diesellue heiratete er und zog die prinzen als seine eignen sölıne in jener höhle auf, in welcher sie Shakespeare vorfithrt. Dort ist der alte tiichtige krieger $z u$ einem frommen und weichherzigen einsiedler geworden. Fr hatte erfahren, was fuir schändliche rïnke, was für heuchelei und falschheit an dem hofe des königs herrsehten, und hielt es deshalb fuir besser die beiden prinzen weit entfernt von jener verpesteten luft ihrer geburtsstätte als einfache, liedere und fromme jigersleute im walde zu erziehen. Dass Shakespeare diesen gegensatz wirklich im auge hatte, beweisen folgende stellen aus dem III. akte des dramas, welche er Belarius in den mund gelegt hat:

'A goodly clay, not to keepe house with such,

Whose Roofe's as lowe as ours: Sleepe Boyes: this gate

Instructs you how t'adore the Heauens; and bowes you

'To a mornings holy office. 'The Gates of Monarches

Are Arch'd so high, that Giants may iet through

And keepe their impious 'lurbonds on, withont

Good morrow to the Sun'. 
Und an einer andern stelle sagt er zu den prinzen, als diese die welt kennen zu lernen wünschen und die höhle des Belarius als 'a Cell of Ignorance: trauuiling a bed, A Prison or a Debtor, that not dares To stride a limit' bezeichnen:

\section{'How you speake!}

Did you but know the Citties Vsuries, And felt them knowingly: the Art o' th' Court, As hard to leaue, as keepe, whose top to climbe Is certaine falling: or so slipp'ry, that The feare's as bad as falling. The toyle o' th' Warre', A paine that onely seemes to seeke out danger, I' th' name of Fame and Honor, which dyes i th' search, And hath as oft a sland'rous Epitaph,

As Record of faire Act. Nay, many times

Doth ill deserue, by doing well: what's worse

Must curt'sie at the Censure'.

Am ende dieser stelle spricht er die worte:

'- But $v p$ to' th' Mountaines,

This is not Hunters Language; he that strikes

The Venison first, shall be the Lord o' th' Feast,

To him the other two shall minister,

And we will feare no poyson, which attends

In place of greater State'.

Shakespeare verschmolz diese erzählung tuber Cymbeline and seine söhne mit der italienischen novelle dadurch, dass er Imogen, des königs tochter zu Ginevra und Leonatus Posthumus, seinen adoptivsohn, zu deren gatten machte. Imogen als tochter Cymbeline's ist damit auch schwester der beiden entfuhrten prinzen, und da es ja der plan des ganzen stückes mit uotwendigkeit verlangte, dass auch diese mit ihr wenigstens einmal zusammengefthrt würden, bevor sich der dramatische knoten löst, so bot sich dazu für den grossen dramatiker die beste gelegenheit da dar, wo Imogen, nachdem sie ihrem tod entronnen, in den bergen allein umherwandert; ja, Shakespeare war genötigt Imogen in diese höhle gehen zu lassen, wofern er nicht seinem drama eine ganz andere wendung hätte geben wollen. Daher trage ich nicht im geringsten zweifel, dass diese begegnungsscene in der höhle des dichters eigenste schöpfung ist. Und wie fein ist gerade diese scene durchdacht, wenn man erwägt, dass Imogen nicht die geringste

1 Hierbei denkt er an sein eigenos schicksal. 
ahnung davon hat, dass sie zu ihren briidern kommt, welche ihrerseits ebenfalls nichts ron ihrer schwester wissen. Mit welcher spannung folgt man ihrem beiderseitigen gespräch, wie ergötzlich ist Imıgen's wunsch, diese einfachen jägersleute zu brtidern zu haben, da sie dann nicht tronerbin wäre und Posthumus ohne widerrede ihrer ältern zum gatten erhalten hätte. Sie sagt (III, 7):

'If Brothers: would it had biu so, that they

Had bin my Fathers Sonnes, then had my prize

Bin lesse, and so more equall ballasting

'To thee, Posthumus'.

Der umstand, dass Imogen wie Sneewitchen ihrem tod entgeht, war dem dichter schon in der novelle des Boccaccio gegeben und gehört mit notwendigkeit zur fabel selbst. Ausserdem ist es nicht die königin, welche in dem, deutschen märchen einen jäger beauftragt Sneewitchen zu töten, sondern Posthumus, der Pisanio befiehlt Imogen umzubringen. Dass im drama die mörderische absicht der königin durch deren arzt Cornelius vereitelt wird, bedingt jener in der italienischen novelle schon vorhandene umstand, welchen Shakespeare beibehalten musste, wollte el nicht seinem drama ein durchaus tragisches ende geben. Imogen verfält daher nur in einen scheintod und kann in folge dessen, obgleich die beiden prinzen sie für wirklich tot halten, wicht in die erde versenkt werden, zumal sie bei ihrem erwachen nach dem plan des dichters Cloten als toten im gewande ihres gatten neben sich finden soll. Ich kann darin durchaus keine beziehung zu dem deutschen märchen finden, in welchem Sneewitchen mehrere male von ihrer stiefmutter selbst vergiftet, aber von den zwergen noch zur rechten zeit gerettet wird. Noch weniger aber kann ich begreifen, wie Karl Schenkl behaupten und sich für tiberzeugt halten kann, dass Shakespeare den stoff zu diesen scenen aus diesem märchen entnommen habe. Man fuihlt es aus all den einzelheiten des ganzen dramatischen verlaufes heraus, dass dies nicht der fall sein kann.

Was die iubrigen punkte unter 2 . betrifft, so kann ich nichts besonders auffallendes darin finden, dass die jägersleute Imogen für ein überirdisches geschöpf halten; denn sie haben in ihrer einsam gelegenen und rauhen höhle kein so schönes wesen wic Imogen erwartet. Der ausiuf des Belarius 
beim anblick der als knabe verkleideteten Imogen, die ja als ein schönes weib im sttick dargestellt wird, scheint mir daher sehr natiirlich:

'By Iupiter an Angell: or if not

An earthly Paragon. Behold Diuinenesse

No elder then a Boy'.

Guiderius sagt zu ihr:

'Were you a woman, youth,

I should woo hard but be your Groome in honesty'.

Ebenso nebensächlicher und aus den umständen sich elgebender art ist der zug, dass Imogen wie Sneewitchen wegen ihrer kochkunst geriihmt wird." Bevor sie die jägersleute in ihrer höhle treffen, sagt Belarius, von der jagd zurïckgekehrt, dass er und Cadwal (Arviragus) koch und diener sein wollten:

'You Polidore haue prou'd best Woodman, and

Are Master of the Feast: Cadwall, and I

Will play the Cooke, and Seruant, 'tis our match!

Aus den letzten worten ersieht man, dass sie eine ganz bestimmte ordnung in ihrem haushalt inne hatten. Derjenige, welcher das meiste wild erlegt, wird vom amte eines kochs entbunden und von den beiden anderen bedient. Dieser vertrag. wird aber nichtig, sobald Imogen hinzukommt. Denn da dieselbe, des jagens nicht kundig, in der höhle zuriickbleibt, so liegt nichts näher, als dass die jiiger sie mit der zubereitung ihrer speisen beauftragen. Belarius sagt $\mathrm{zu}$ ihr, als sie sich unwol fühlt:

'Pray be not sicke,

For you must be our Huswife',

worauf sie antwortet:

'Wcll, or ill,

I ain bound to you'.

Sie nimmt dieses amt gem an, um ilmen gleichsam fuir die liebevolle aufnahme, welche sie bei ihnen gefunden, einen gegendienst $\mathrm{zu}$ leisten. Dass sie die jüger ob ihrer kochkunst loben, scheint mir sehr nattirlich, da ein tadel doch keineswegs am platze wäre. Das ganze stück zielt eben auf ihre verherrlichung hin und der dichter versäumt nicht ihr auch in solchen dingen lob zu zollen. Arṿiragus rithmt Imogen auch ihres gesanges wegen. Begeistert ruft er aus:

'How Angell-like he sings'.

I S. s. 26 die anmerkung: 
Und Belarius sagt von ihr:

'Nobly he yoakes

A smiling, with a sigh; as if the sighe

Was that it was, for not being such a Smile:

The Smile, mocking the Sigh, that it would flye

From so diuine a Temple, to commix

With windes, that Saylors raile at'.

Da die jiiger Imogen so' sehr liebgewonnen, so ist es denn anch sehr natiirlich, wenn sie über den verlust derselben, gleich wie die zwerge tiber Sneewitchen, trauern und klagen. Hier gewährt denn auch der dichter einen noch besonderen einblick in das gemüt der beiden brüder. Die gefühlvolle seite ihres charakters tritt an dieser stelle besonders hervor.

Was endlich die erwähnung des rotkehlchens bei Shakespeare betrifft, so ist es ein ganz allgemeiner zug der mythe ältester zeiten, dass dieser vogel blätter und blumen auf das antlitz eines toten menschen trägt, welchen er im walde findet. Einen treff'lichen beleg dafiir, dass dies auch in England bekannt war, bildet die strophe einer sehr volksttimlichen ballade aus dem 17. jahrhundert, betitelt: 'The Children in the Wood'.' Von diesen kinderm, - welche von ihren verstorbenen ältern ihrem oheim zur pflege anvertraut waren, aber auf dessen anstiften von zwei schurken im walde ermordet werden sollten und schliesslich, von diesen verlassen, hungers starben, - heisst es in dieser ballade, vers $123 \mathrm{ff}$.:

'In one anothers armes they dyed,

As wanting due relief:

No burial 'this' pretty 'pair'

Of any man receives,

'Till Robin-red-breast piously

Did cover them with leaves'.

Dies wird aber nur von dem rotkehlchen berichtet. Nun aber erscheint in dem deutschen märchen nicht dieser vogel am sarge Sneewitchen's, sondern es beginnen eule, rabe und taube ihre klagelieder anzustimmen. Daraus folgt, dass Shake-

1 Siehe Percy: 'Reliques of Ancient Englisch Poetry', London 1875, s. 239. Diese ballade ist nach Percy aus einem älteren stiicke genommen, betitelt: 'Two lamentable Tragedies;' the one of the murder of maister Beech, a chandler in Thames-streete etc. 'The other of a young child murthered in a wood by two miffins, with the consent of his uncle. By Rob. Yarrington 1601 tto'. 
speare mit der sagenhaften bedentung der vögel sehr wolbekannt war und diesen zug von dem rotkehlchen nicht aus dem märchen entlehnt zu haben braucht.

Wenn wir nunmehr die punkte, welche wir gegen die Schenkl's aufgestellt haben, zusammenfassen, so glaube ich die behauptung Schenkl's, das deutsche märchen von Sneewitchen sei eine dritte quelle zu Shakespeare's Cymbeline, als unrichtig hingestellt und damit zurtickgewiesen zu haben. Es sind iberhaupt einige griunde vorhanden, welche zweifel zulassen, ob dieses märchen, welches in Hessen entstanden sein soll, zur zeit Shakespeare's in England bekannt war.

Jakob Grimm weiss davon nichts, ebenso Benjamin Tabart, welcher auf s. 71-102 des 21. bandes der Quarterly Review vierundzwanzig erzählungen für kinder (Nursery tales) unter dem titel veröffentlicht hat: 'Fairy Tales or the Lilliputian cabinet, containing 24 choice pieces of funcy and fiction'.

Tabart erwähnt darin nichts von dem märchen von Sneewitchen, dagegen erzählt er das von dem 'Machandel-Boom', welches im anfang ${ }^{1}$ ganz und gar mit jenem ubereinstimmt, und in Schottland bekannt war. Tabart sagt:

'Dr. Leyden had there heard a nursery tale in which the spirit of a child in the form of a bird is supposed to whistle the following verse to its father:

$$
\text { Pew - mew - pew - mew }
$$

My minny me slew'.

Von diesem märchen kann aber ebenso, wie von dem über Sneewitchen nicht nachgewiesen werden, dass es Shakespeare gekannt hat, weil in keinem seiner werke eine stelle zu finden ist, welche darauf anspielt. Dagegen kannte der grosse dramatiker den fliederbaum als ein symbol der sorge und des kummers. ${ }^{2}$ In der 2. scene des IV. aktes von Cymbeline heisst es:

1 In diesem märchen wïnscht sich eine frau ein kind, dessen gesichtsfarbe so rot wie blut und weiss wie schnee sei. Bald geht ihr wunsch in erfillung, aber sie stirbt. Ihr gatte nimmt sich darauf ein anderes weib, welches ihm einen knaben zuführt. Derselbe ist aber im vergleich zu seiner stiefschwester sehr hässlich und wird deshalb von seiner mutter getötet, die ihre stieftochter ausserordentlich liebt. - Wie dieser zug schon durchaus verschieden ist von dem weiteren verlauf des märchens von Sneewitchen, so auch die iibrigen.

2 Die deutsche mythe scheint diesen zug nicht zu kennen, denn Grimm gibt eine andere bedeutung dieses baumes. Er sagt auf s. 122 
'Grow patient,

And let the stinking-Elder, (Greefe) vntwine

His perishing roote, with the encreasing Vine'.

Dass dem flieder diese bedeutung beigelegt wurde, hat wahrscheinlich seinen grund in der sage, dass sich Judas Ischariot an einem fliederbaum erhängt habe. Darauf bezieht sich eine stelle der 2. scene des V. aktes in Love's Labour's Lost. Daselbst sagt Biron zu Holifernes:

'Well follow'd,

Iudas was hang'd on an Elder'.

Fassen wir nun zum schluss die folgerungen, welche sich aus der untersuchung der einzelnen erzählungen in ihrem rerhältniss zu dem drama Cymbeline ergeben, nochmals zusammen, so liefern diese das gesammtergebniss, dass Shakespeare den stoff $\mathrm{zu}$ seinem drama lediglich aus der IX. novelle des II. tags des Decamerone von Boccaccio und der chronik des Holinshed genommen, letzterer auch sprachliches entlehnt hat; dass die verbindung beider erzählungen seine eigene schöpfung ist und dass er weder das altfranzösische mirakelspiel, noch 'Westward for Smelts', noch das märchen von Sneewitchen irgend wie gekannt und benutzt hat.

WURzEN.

B. LEONHARDT.

seiner Mythologie: 'Flieder oder hollunder hilft gegen zahnweh und fieber: der fieberkranke steckt, ohne ein wort dabei zu sprechen, einen fliederzweig in die erde. Da bleibt das fieber haften, und hängt sich dann an den, der zutiillig iiber die stiitte kommt'. 